Sultan Qaboos University Journal of Arts \& Social Sciences

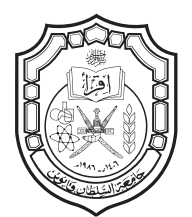

جامعة السلطان قابوس

مجلة الآداب والعلوم الاجتمأعية

\title{
صِفة المرأة ودلالاتها في البنية الصرفية صيغتا فَعول وفاعل في الشّعر العربيّ أنموذجًا
}

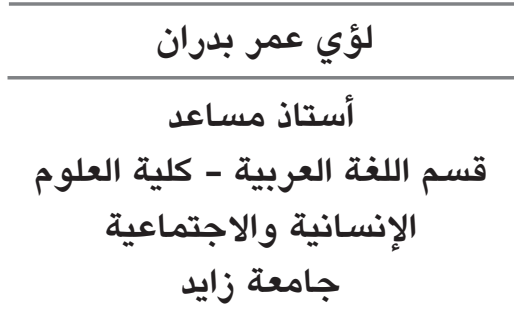

loaybadran@yahoo.com 


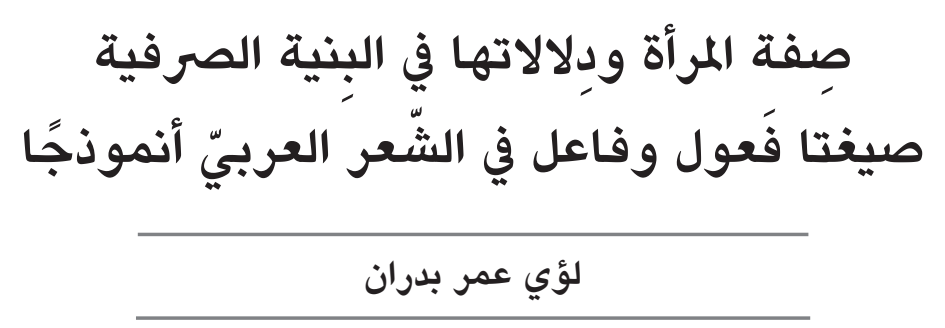

الملخص

نظرا لأهمية درس التأنيث في اللغة العربية واتصاله بالعديد من دروس النحو واللغة، تتناول هذه الدراسة الحقول الدلالية للمرأة في بنيتي:

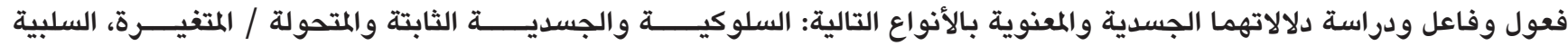

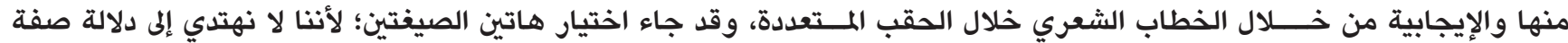
هذين الوزنين في أنهما عائدان على مذكر أم مؤنث دون تحديد جنس الموصوف، بيد أن صفات فئ المات المرأة في البنية الصرفية للوزنين (فعول

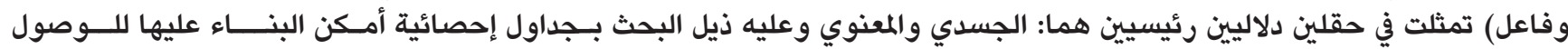
إلى النتائج والتوصيات المتعلقة بالتصنيفات السابقة ولتئ.

الكلمات المفتاحية: تأنيث، تذكير، صفة، حقل دلالي، المرأة.

\title{
Women's Adjectives and its Signification in the Morphological Structure: Forms of Fa'il \& Fa'uul, In Arabic poetry as examples
}

\section{Loay Omar Badran}

\begin{abstract}
:
According to the importance of feminization in the Arabic Language and its relatedness to many fields of grammar and linguistics; this study discusses the semantic fields of women's adjectives and descriptions in the structures of: Fa'uul \& Fa'il. The study will highlight the physical and behavioral significations according to these types: Positive or negative lasting and changeable behaviors and physical attitudes; by studying the Poetic Discourse throughout different eras. I have chosen these two forms because we cannot figure out the gender of the described person without mentioning it. Also, women's adjectives in the Morphological structure for the forms (Fa'il and Fa'uul) are found in two major semantic domains which are: physical and behavioral aspects. In this study I have included statistical tables that I was able to work on; in order to include results and recommendations related to the previous categorizations.
\end{abstract}

Keywords: Adjectives; Feminization; Masculinization; Semantic Fields; Women. 
بغير علامة تختلف عن المقيس بعلامة، من هنا تأتي أهمية هذه

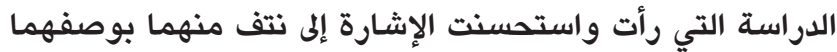

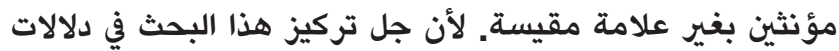
هاتين الصفتين بوصفهما مؤنثين للمرأة بغير علامة الامة التأنيث

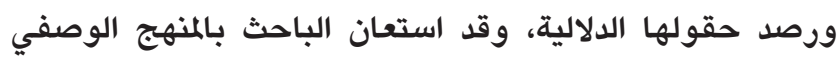
التحليلي الذي يتناسب وهذه الدراسة.

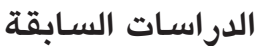
إبراهيم بركات (911) التأنيث في اللغة العربية. درس المؤلف في

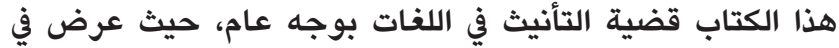
كثير من الإيجاز دراسة هذه القضية في اللغات الأخرى مشيرا إلى

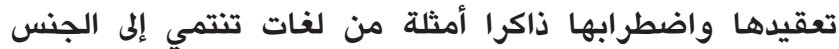

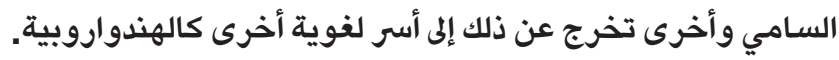

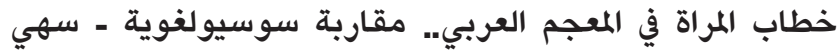
نعحة 10 أ. يتبصر كتاب خطاب المرأة في المعجم العربي؛ مقارية

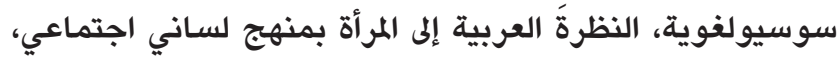

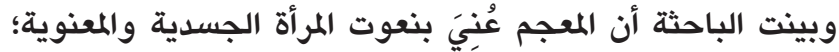

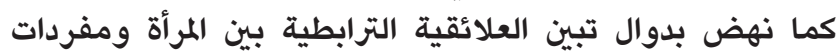

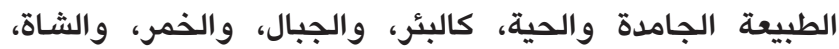

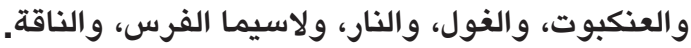

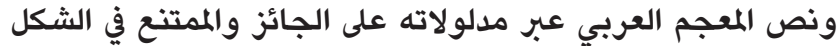

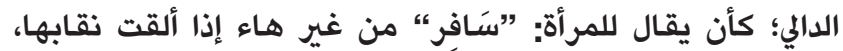

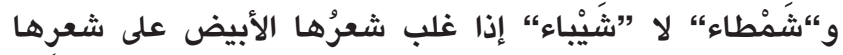

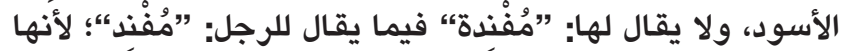

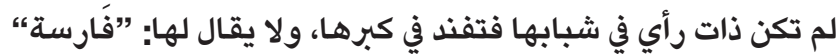

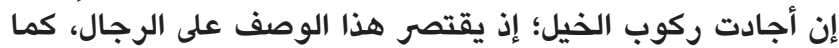

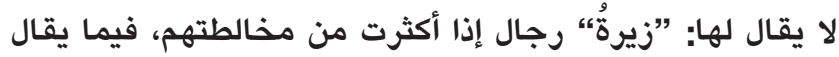
”زير“" لمن يكثر مخالطة النساء من الرجال. وفي الدراسة سعيُ دؤوبْ يستَكَنْه الإجابة عن الأسئلة المركزية

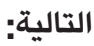
- ما مفهوم الذكورة والأنوثة في النسق الدالي المعجمي في ضوء الأنساق المعرفية للثقافة العربية؟ وهل الأوكل اللغة العربية مؤدلجة النجاء

تمركز الذكورة وتحابيها، وتهمش الأنوثة وتقصيها؟

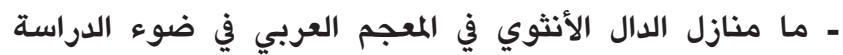

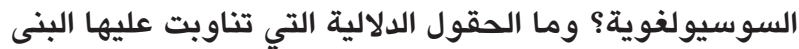

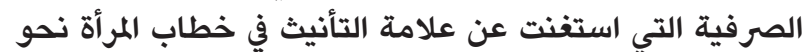

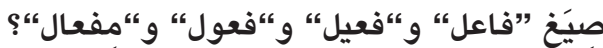

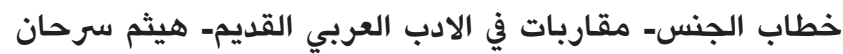

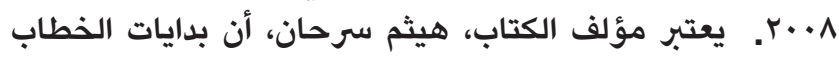

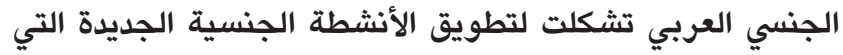

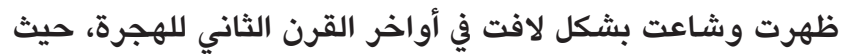

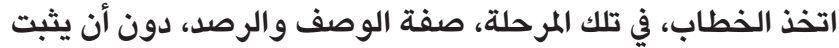
ويسجل مفاهيم نقدية تُذكر، باستثناء ما قدمه الجاحظ من رؤى التى وأفكار نقدية مهمة في سائر أعماله، وخاصة فئماء في رسالتيه

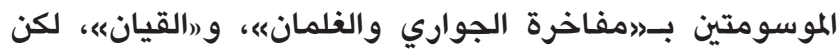

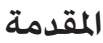

من معاني صيغة فعول بوصفها صفة أنها تأتي بمعنى صيغة

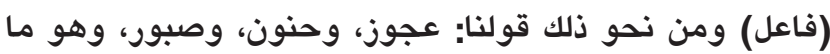

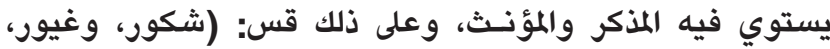

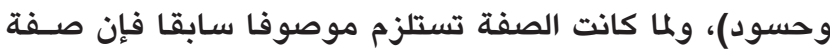
الوزن فعول تستلزم موصوفا سابقا أيضـا خشية اللبس في في إنان

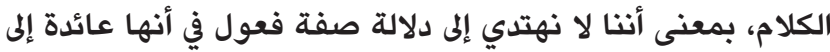

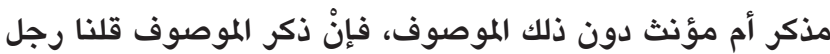
شكور وامرأة شكور، ورجل قتيل وامرأة قتيل، بذلك أمن اللبس،

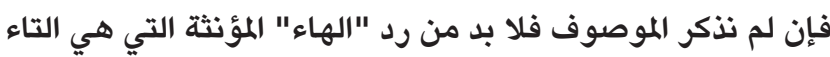
إلى صيغة "فعول"، ولتبين هذا الأمر ننظر إلى الجملة الآتية: "فئ

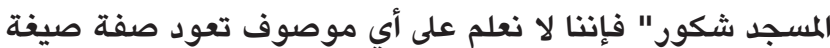

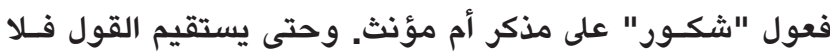

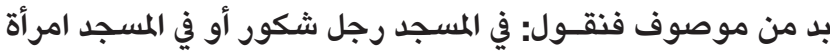

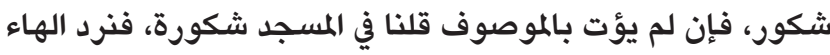

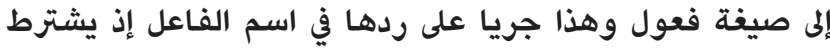

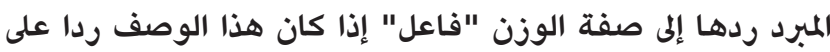

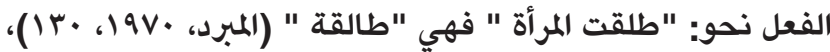

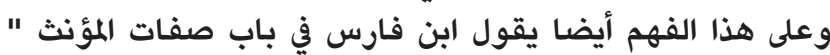

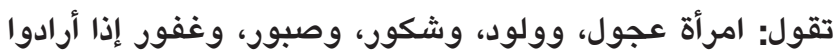

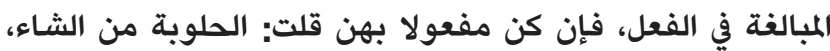

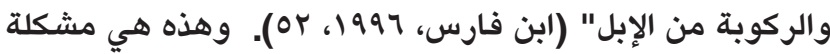

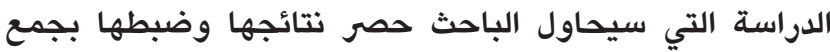

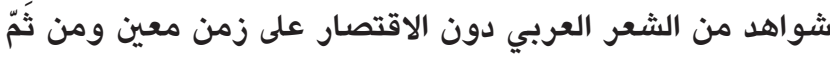
تحليلها وتذييل حلولها في نهاية البحث.

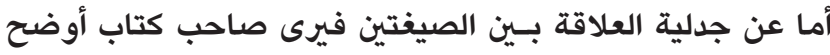

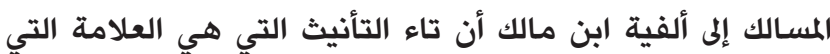

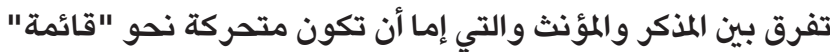

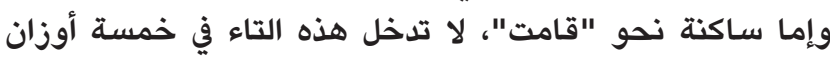

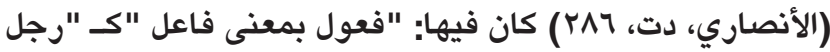

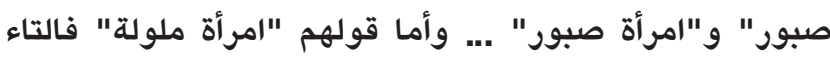

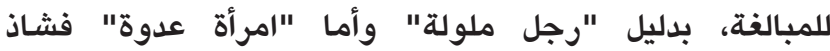

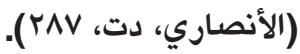
وبناء على هذا الفهم فإن التاء قد تلحق الصفة (فعول) إن كان

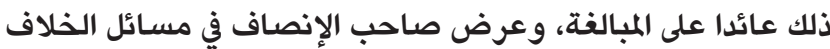

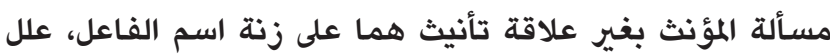

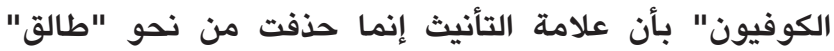

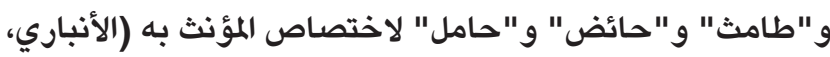

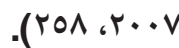
أما البصريون فذهبوا إلى أنه "إنما حذفت منه علامة التأنيث لأنهم قصدوا به النسب ولم يجروه على الفعل، وذهب بعضهم إلى إلى أنهم إنما حذفوا علامة التأنيث منه؛ لأنهم حملوه على على المعنى كأنها بانهم

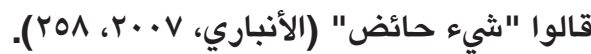

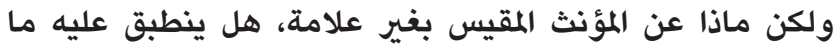

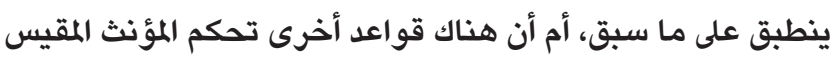


الدلالة: حركي متغير، ومن ذلك قول الشاعر كثير عزة:

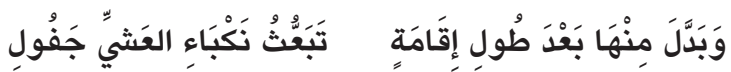

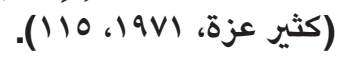
rـ الصفة: خرود. الدلالة: المرأة البكر التي لم تمس قط (لسان

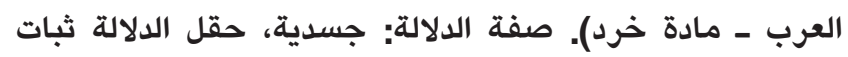

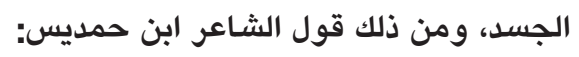

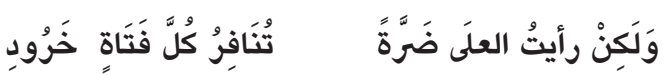

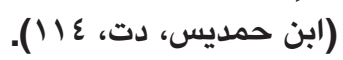

ع- الصفة: خروس. الدلالة: المرأة البكر في أول بطن تحمله (لسان

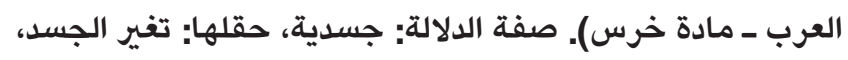
واستعيرت لصفات أخرى كقول الشاعر العرجي: وِشَاحَاهُ عَلَى كَشْحِ هَضِيمِ خَرُوسٍ حِجْلهُ وَيَجُولُ مِنْهُ

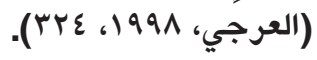

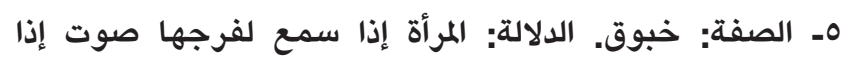

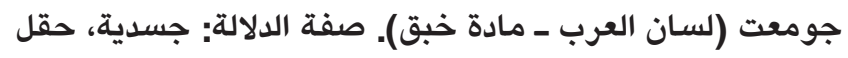

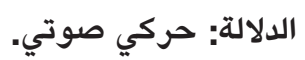
7- الصفة: حضوف. الدلالة: المرأة كثيرة الضراط (لسان العرب مادة ضفف). صفة الدلالة: جسدية، حقل الدلالة صوتي. V- الصفة: خفوت. الدلالة: المرأة الهزيلة (لسان العرب ـ مادة الدادية

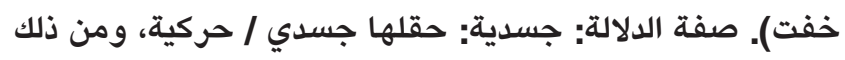

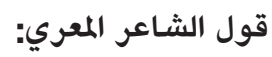

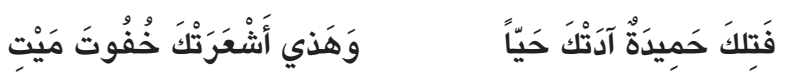

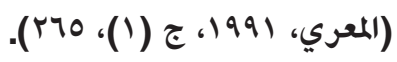

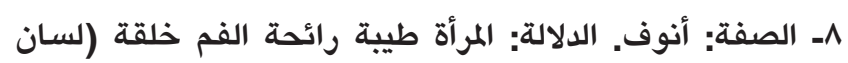

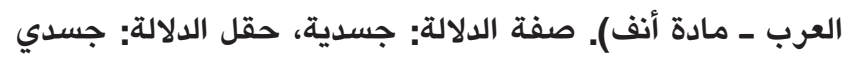
رائحة،ومن ذلك قول الشاعر ابن حيوس:

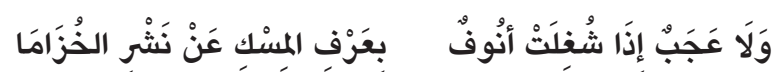

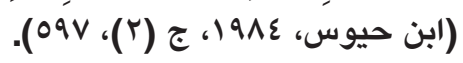

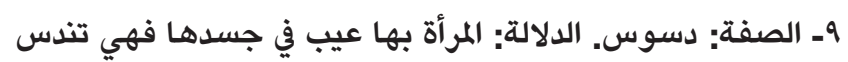

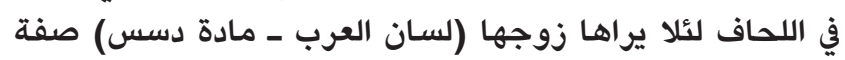
الدلالة: جسدية، حقل الدلالة: جسدي / حركي.

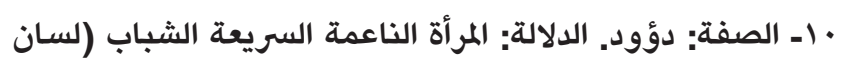

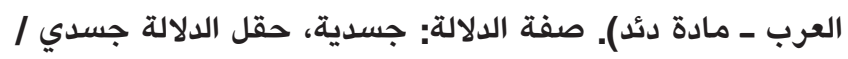

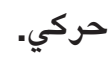

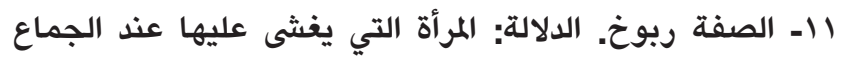

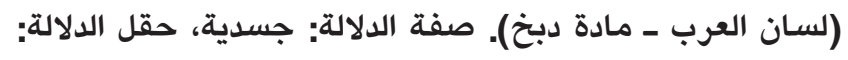

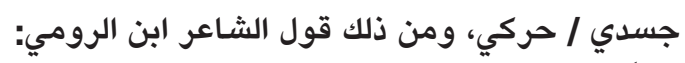

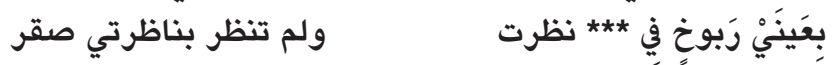

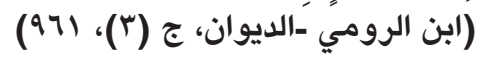

رغم ريادة الجاحظ في حقل الجنسانية، إلا أنه حجب جزءاً كبيراً

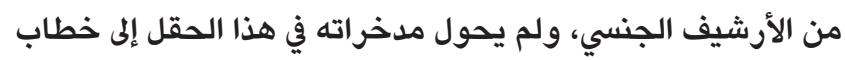

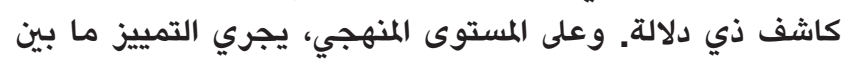

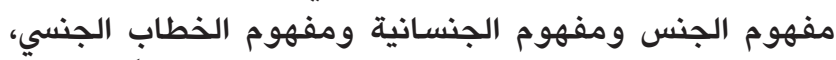

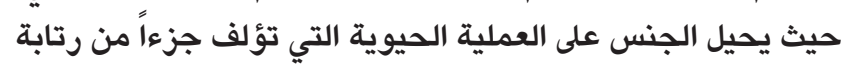

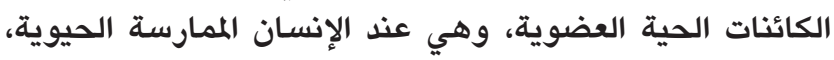

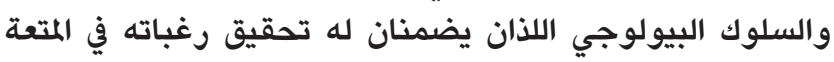

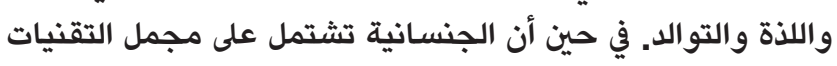

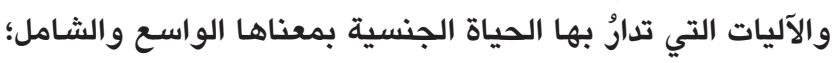

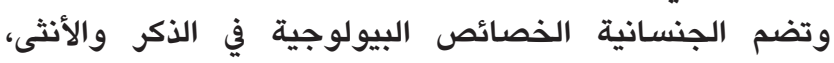

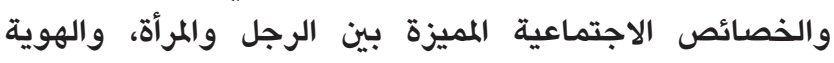

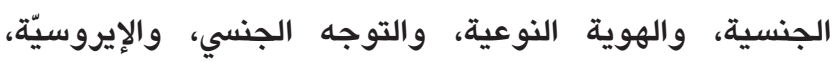

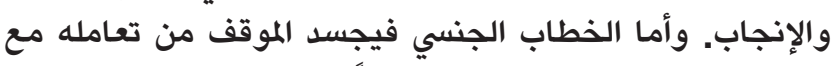

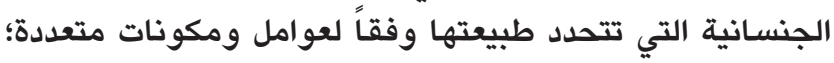

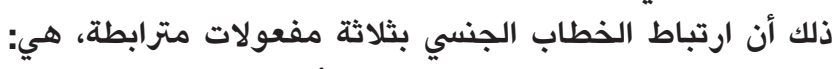

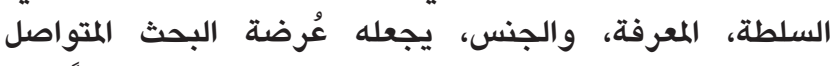

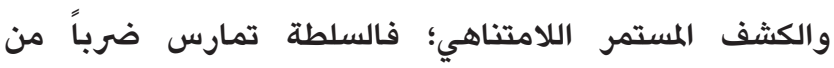

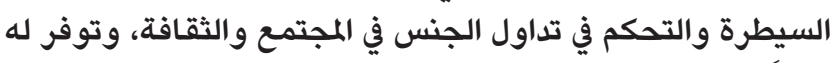

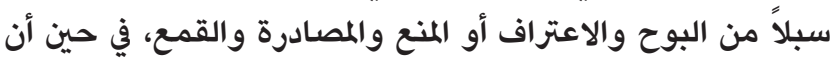

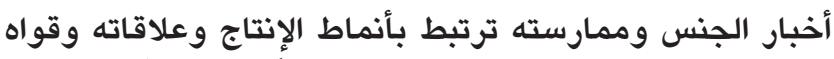

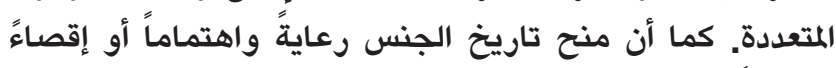

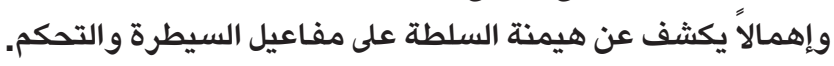

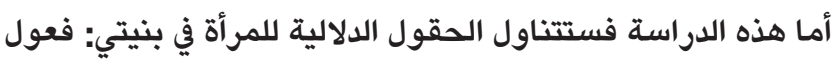

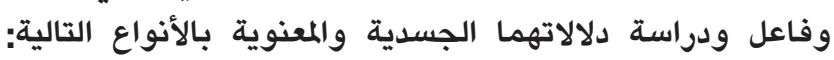

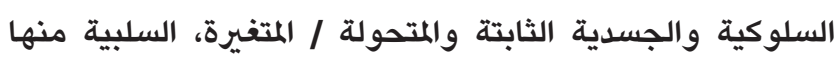

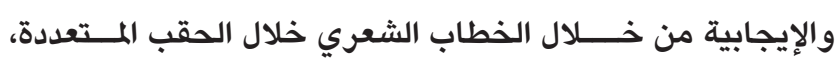

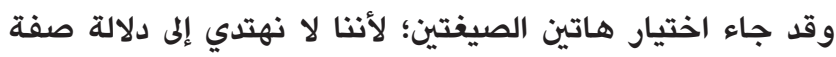

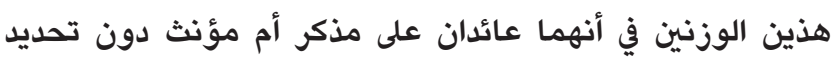

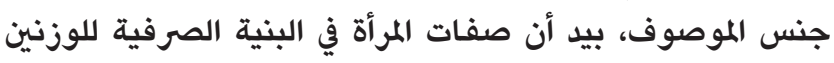

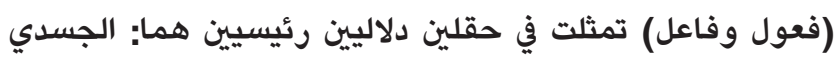
والمعنوي وعليه يكون تذييل البحث كالتالي: أولا - صفات المرأة في البنية الصرفية / فعول.

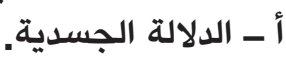

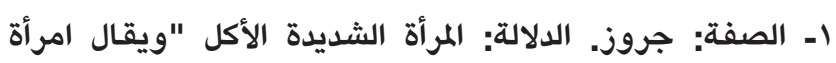

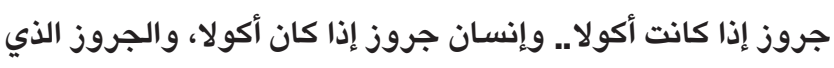

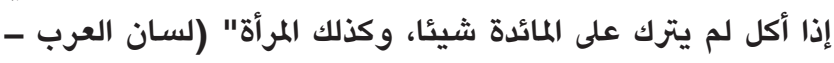

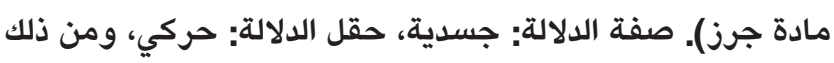
قول الشاعر ابن زريق:

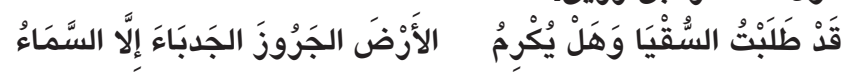

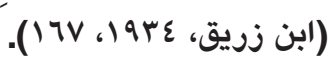

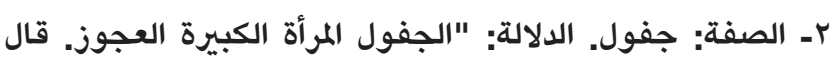

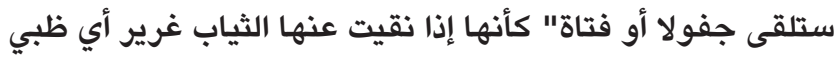

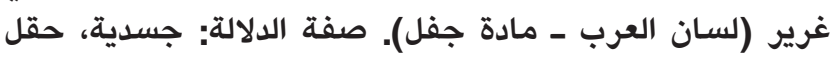


^اـ الصفة: فشوش. الدلالة: المرأة الرخوة (لسان العرب ــمادة رخو). صفة الدلالة: جسدية، حقل الدلالة: جسدي حركي، من ذلك قول رؤبة بن العجاج:

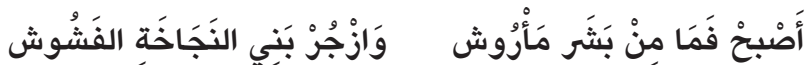

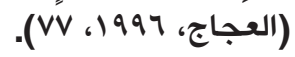
9 اـ الصفة: قشور. الدلالة: المرأة التي لا تحيض (لسـان العرب ـ مادة قشر). صفة الدلالة: جسدية، حقل الدلالة: جسدي ثابت. •r- الصفة كفوت. الدلالة: المرأة الشديدة الستر، المتسترة (لسـان

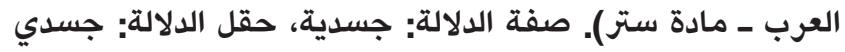
حركي. ومن ذلك قول الشّاعر ابن طباطبا:

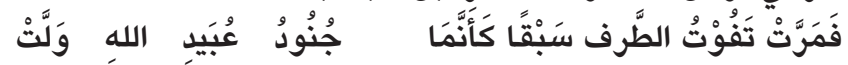

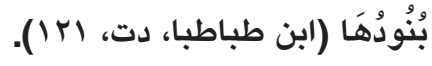

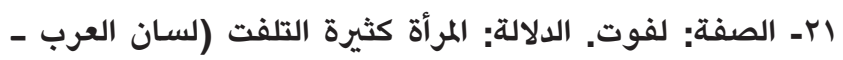
مادة لفت). صفة الدلالة: جسدية، حقل الدلالة: جسدي حركي. من ذلك قول الحيص بيص:

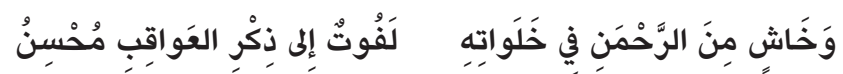

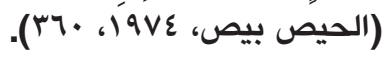
rr- الصفة: مصوص. الدلالة: المرأة التي يمتصّ رحمُها الماء

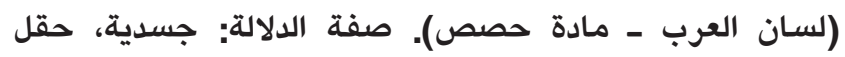
الدلالة: جسدي حركي، ومنه قول الشاعر الصنوبري على الى

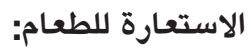

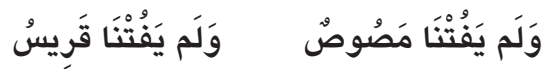

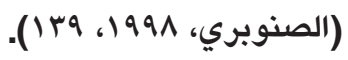
بrـ الصفة: نزور. الدلالة: المرأة قليلة الولد والكلام (لسـان العرب

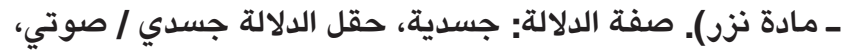
ومنه قول الشاعر ابن دراج القسطلي:

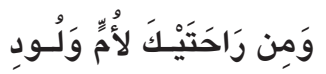

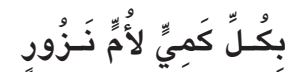

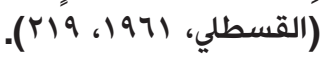

ع ז- الصفة: نعوس. الدلالة: المرأة كثيرة النعاس والنوم (لسـان

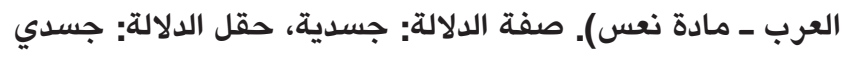
حركي، واستعار هذه الصفة الشاعر الراعي النميري للناقة في

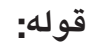

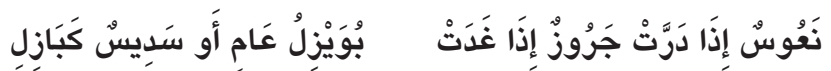

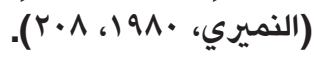
هـ ـ الصفة نفور. الدلالة: المرأة النافرة من كل شيء (لسـان العرب ـ مادة نفر). صفة الدلالة: جسدية، حقل الدلالة: جسدي حركي، وتستوي الصفة مع المذكر كقول الشاعر الطغرائي:

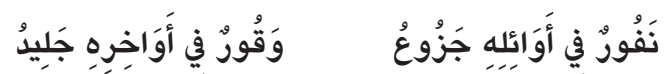
(الطغرَائي، دت،
واستعيرت الصفة لطرف عين المرأة، سمة جمالية، يقول ابن الرومي أيضا: كم ذاتِ طرفٍ ربوخٍ

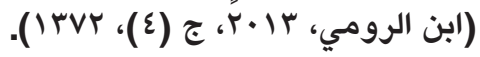
ومنه قول الشاعر فتيان الشاغوري: هـر رَبوض

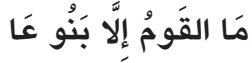
(الشـاغوري، دت، 0 • (1) ). r إ - الصفة: ردوم. الدلالة: المرأة كثيرة الضراط (لسان العرب، مادة ردم). صفة الدلالة: جسدية، حقل الدلالة: جسدي / صوتي. r ا ـ الصفة: سكوت. الدلالة: المرأة كثيرة السكوت لا تتكلم (لسان العرب، مادة سكت). صفة الدلالة: جسدية، حقل الدلالة، جسدي / صوتي، ومن ذلك قول الشاعر الوأواء الدمشقي: لَوْ رَأَتْهُ العِيدَانُ وَهْيَ سَكُوتُ عَلَّمَتْهُ سرَّا بَلَا أَوتَار

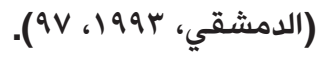

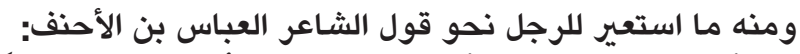

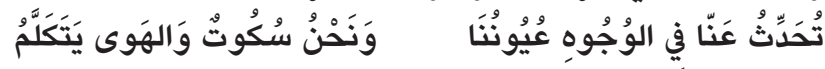

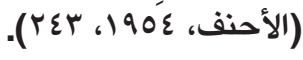

ع اــ الصفة: الطروح. الدلالة: المرأة تطرح عنها ثوبها ثقة بحسن

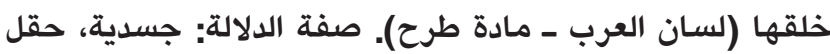
الدلالة: جسدي / حركي، ومن ذلك قول الشـاعر أبي ذؤيب الهذلي وقد استعارها للنوى البعيدة.

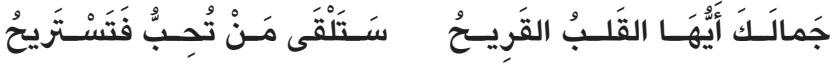

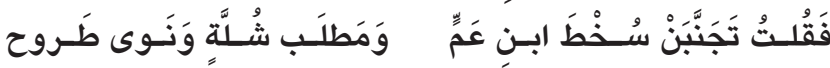

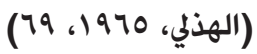
1اـ الصفة: عدوس. الدلالة: المرأة قوية السير (لسان العرب ـ مادة عدس). صفة الدلالة: جسدية، حقل الدلالة: جسدي / حركي، واستعارها الشاعر جرير للناقة، نحو قوله:

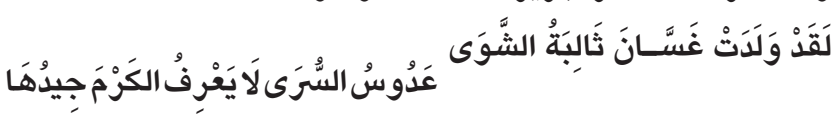

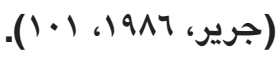

الـ الصفة: عروب. الدلالة: المرأة الضاحكة المتحبية إلى زوجها

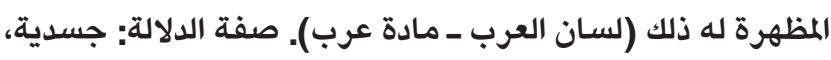
حقل الدلالة: جسدي حركي صوتي، ومن ذلك قول الشاعر ابن هانئ الأندلسي

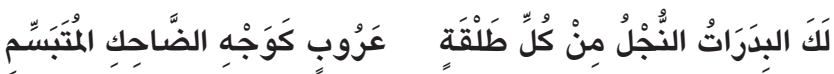

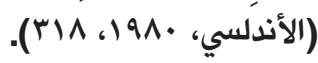

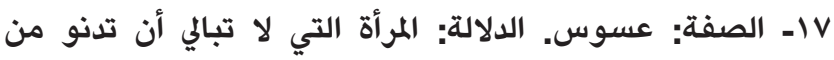
الرجال (لسان العرب ـ مادة عرب). صفة الدلالة: جسدية، حقل

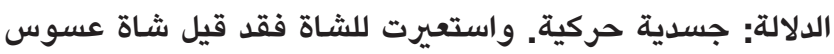
وفيها عسس وأهل نجد يقولون عساس وهي من الإبل خاصة تسمى الضجور (الأصمعي، 19AV، 11). 
أَلَا يَا حَمَامَاتِ الحِمَى عُدنَ عَوْدَةً

(قيس بن الملوح، 1999، 9019 ).

r T - الصفة: بسوس. الدلالة: " البَسُوسُ اسم امرأَة وهي خالة

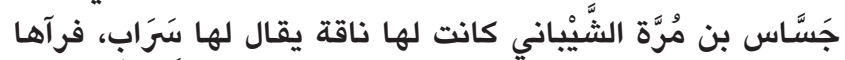

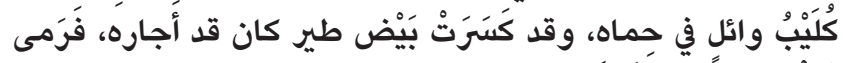

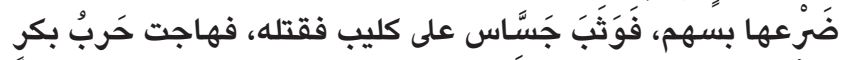

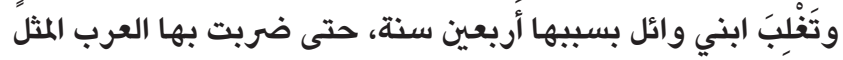

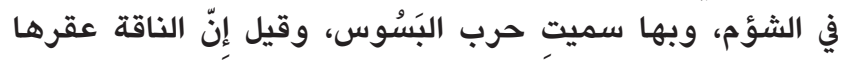

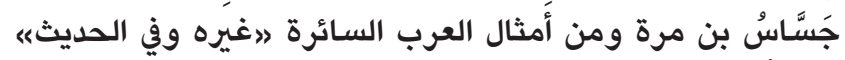

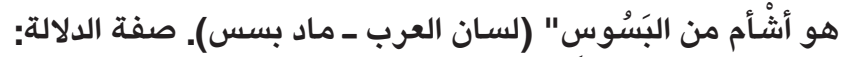

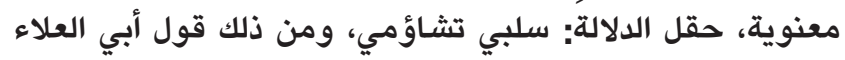

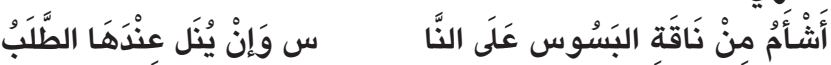

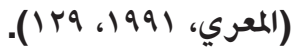

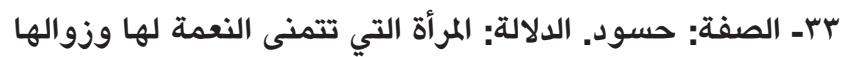

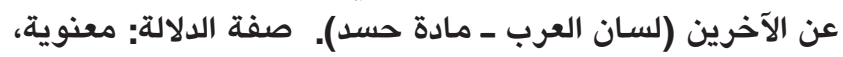
حقل الدلالة: سلبي: شر، ومن ذلك قول الشاعر كشاجم الرملي: لََ تُشْمَنَّ بِيَ الحَسُودَ بِرَدِّهِ

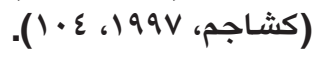
ومنه قول الشاعر فتيان الشاغوري:

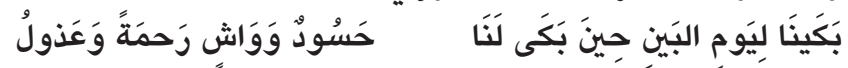

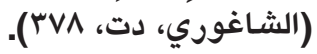

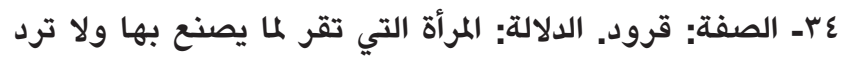

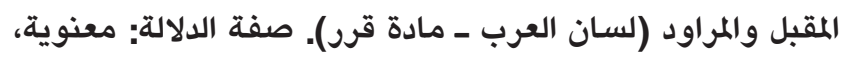

$$
\text { حقل الدلالة: سلوكي/ سلبي. }
$$

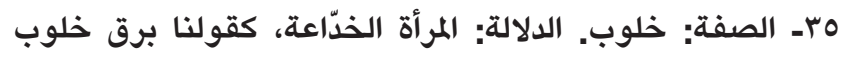

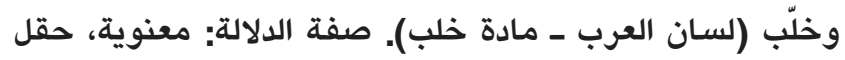

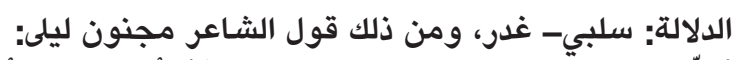

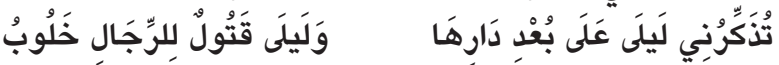

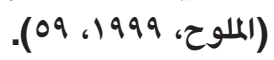

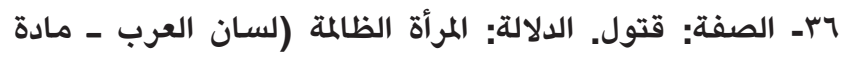

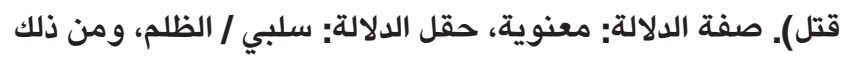
قول الشاعر قيس بن الملوح السالف.

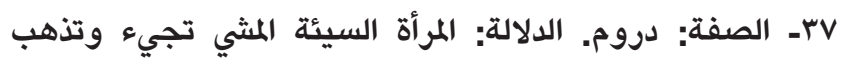

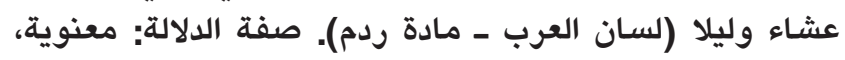

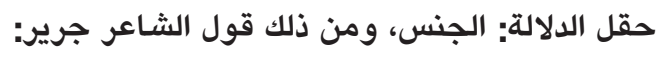

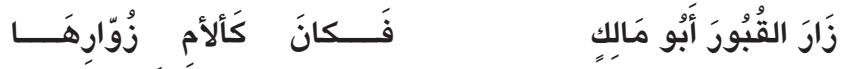

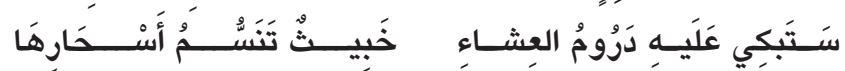

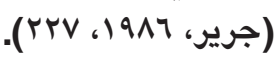

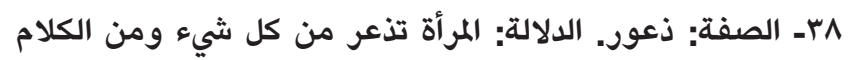

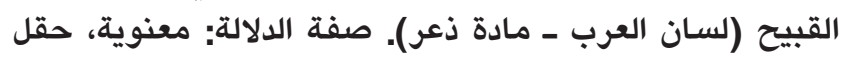

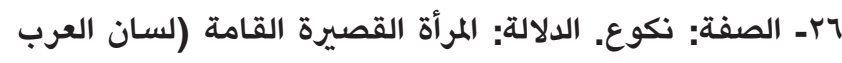
مادة، نكع). صفة الدلالة: جسدية، حقل الدلالة: جسدي ثابت.

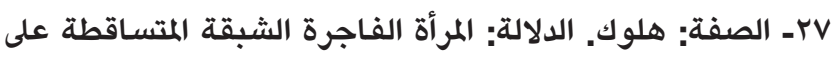

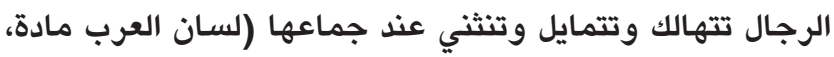

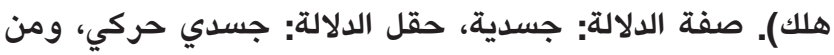

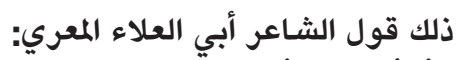

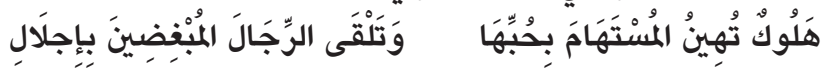

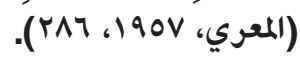

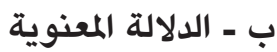

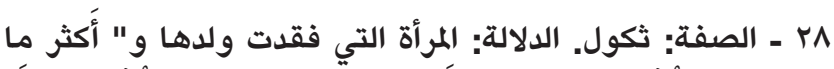

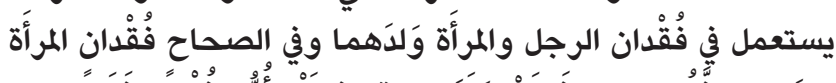

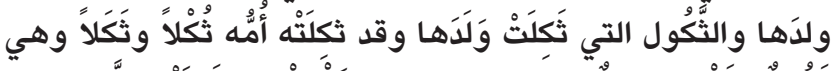

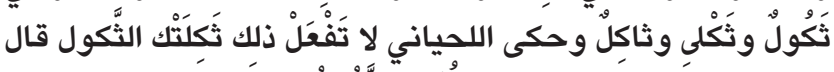

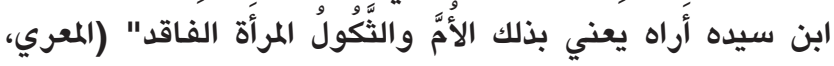

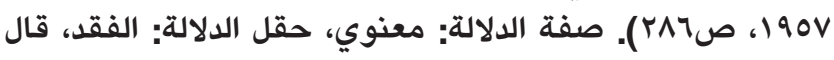
الشاعر المتنبي: مَلَطيَةُ أُمْهُ لِلَبَنِنِ ثَكُولُ وَكَرَّتْ فَمَرَّتْ في دِماءِ مَلَطْيَةٍ

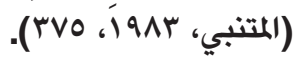

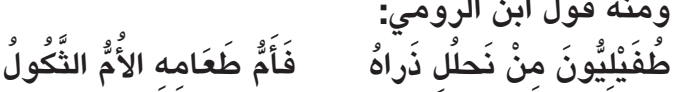

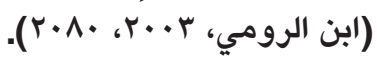

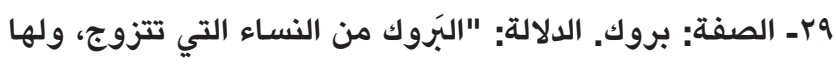

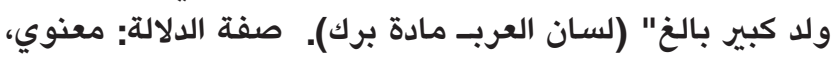
حقل الدلالة: الزواج.

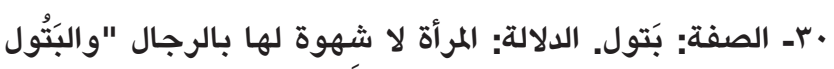

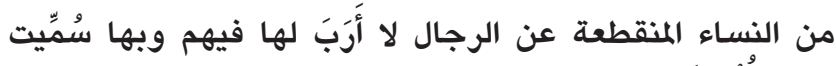

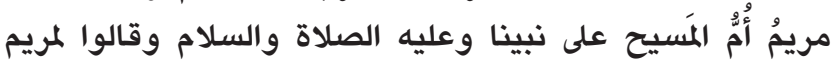

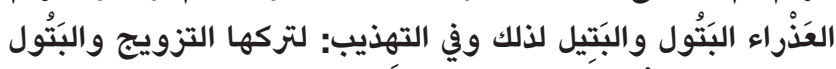

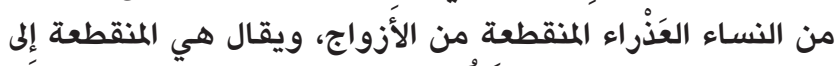

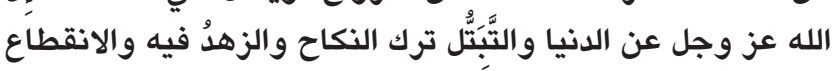

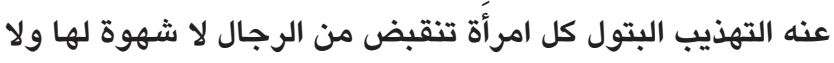

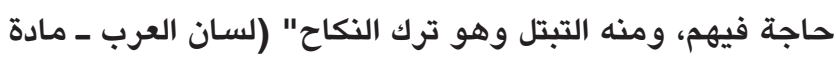

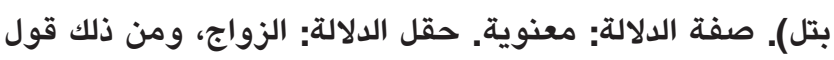
وَبِتُّ وَزَوجَتِي بِكرٌ بَتُولُ

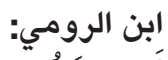

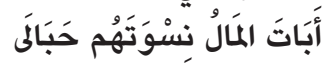

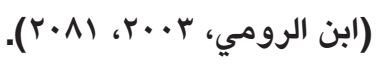

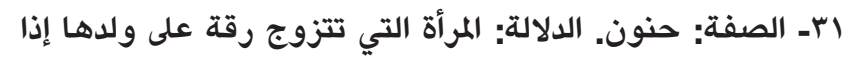

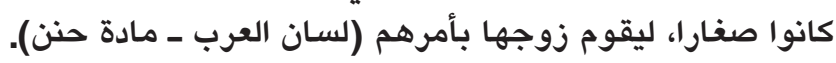

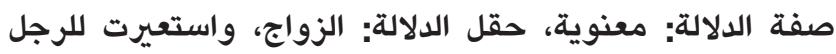
الحانّ أيضًا كقول الشاعر قيس بن الملوّح: 
العرب ـ مادة عرس). صفة الدلالة: معنوية، حقل الدلالة: الزواج،

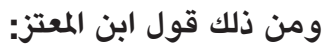

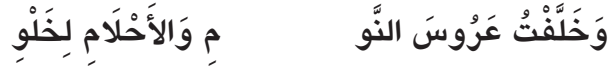

$$
\begin{aligned}
& \text { (ابن المعتز، دت، عهV). }
\end{aligned}
$$

7؟- الصفة: عطوف. الدلالة: المرأة المحبة لزوجها الحانية على

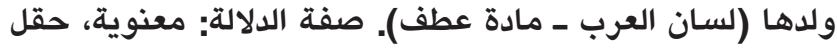
الدلالة: الزواج، ومن ذلك قول الشاعر ابن حمديس:

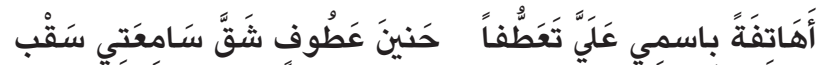

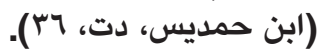

VV V الصفة: علوق. الدلالة: المرأة التي لا تحب زوجها (لسان

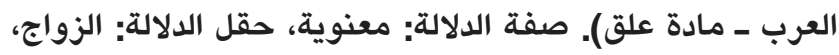

ومنه قول الشاعر جرير عندما أخذته علوق عن صاحبيه:

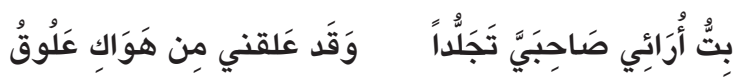

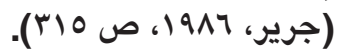

^عـ- الصفة: غدور. الدلالة: المرأة شديدة الغدر (لسان العرب مادة

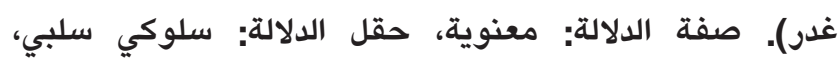
واستعارها الشاعر أحمد شوقي للسفينة نحو قوله:

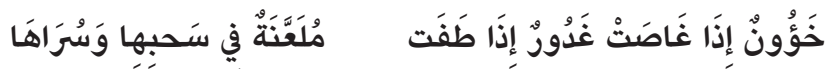

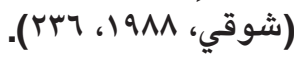
qعـ الصفة: غضوب. الدلالة: المرأة الشديدة الفضب (لسان العرب

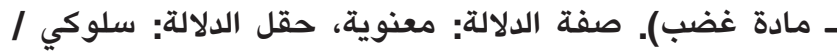
سلبي، ومن ذلك قول الشاعر النابغة الذبياني: غَضُوبْ وَإنْ نَالَتْ رضًى لَم تُزَهزق

$$
\text { إِذَا غَضَبَتْ لَمْ يَشعُرِ الحَيُّ أَنَّها }
$$

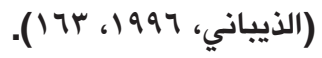

•ــ الصفة: فروق. الدلالة: الكثيرة الخوف لسان العرب ــ مادة

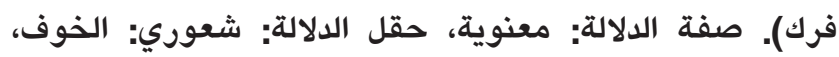
واستوت الصفة مع المذكر نحو قول الحيص بيص: فُرُوقُ الأَعَادِي فَهْوَ خَشَيَانُ جَائعُ

$$
\text { تَدَافَعَ غَرْثانَ المَطِيَّة والحَشَا }
$$

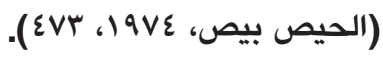

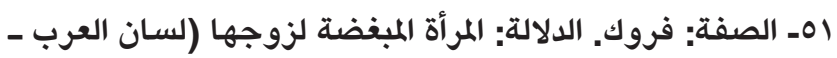

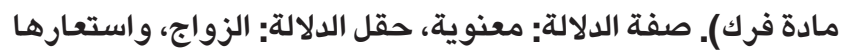

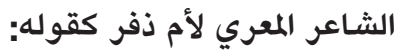

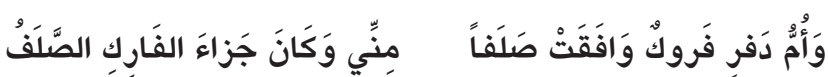

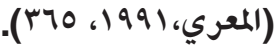

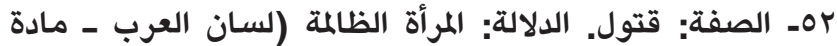

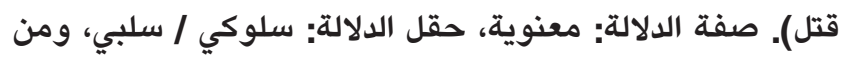

الدلالة: إيجابي الخوف/ شعوري. ومن ذلك قول الشاعر بشار بن برد:

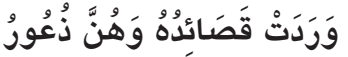

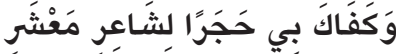

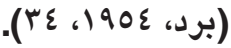

qج ـ الصفة: رؤود. الدلالة: المرأة التي تدخل بيوت الجيران (لسان

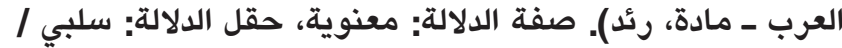
سلوكي، ومن ذلك قول الشاعر ذي الرمة: تَكسُوهُ كُلّْ هَيفَةِ رَؤودِ

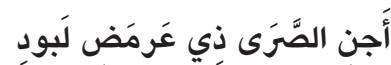

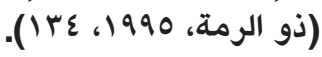
•ــ الصفة: صبور. الدلالة: المرأة الصابرة (لسان العرب ـ مادة

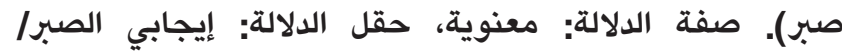

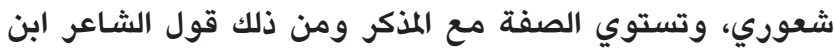

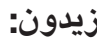

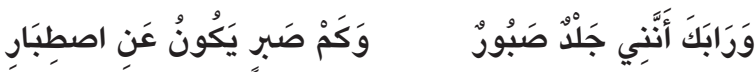

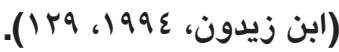
اعـ- الصفة: شكور. الدلالة: المرأة المجتهدة في شكر ربها (لسان السان العرب ـ مادة شكر). صفة الدلالة: معنوية، حقل الدلالة: إيجابي / سلوكي، وهي مما يستوي مع الذكر، كقول الشاعر ابن الأبار: إصَاخَتُهُ إلى عَبْدِ شَكور وَأَسْنَى البَذْل من مَوْوَلَ جَوادٍ

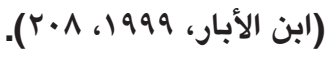

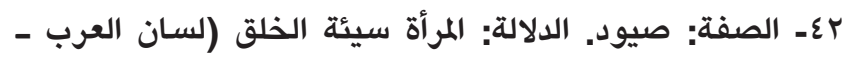

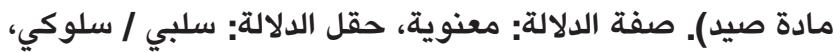

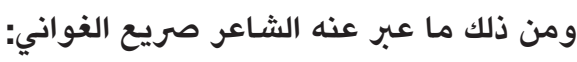
وَطَرفُها مَريضُ (مسلم بن الوليد، دت، و (190). rاع- الصفة: عجول. الدلالة: المرأة الثكلى الواله التي فقدت ولدها

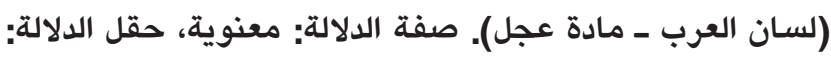

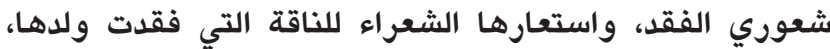
وهي غاية في الفقد والحزن نحو قول الخنساء:

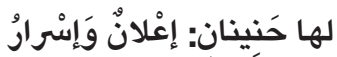
وَمَا عَجُولْ عَلى بَوِّ تُطِيفُ بِهِ

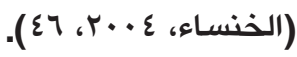

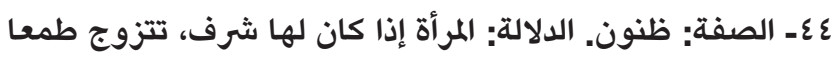
في ولدها وقد أسنت (لسان العرب ـ مادة ظنن). صفة الدلالة: معنوية، حقل الدلالة: إيجابي سلوكي / الزواج، ومن ذلك الك قول الكال

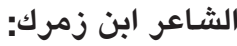

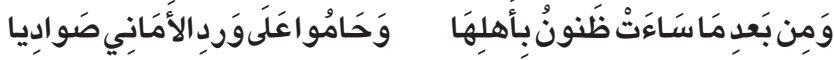

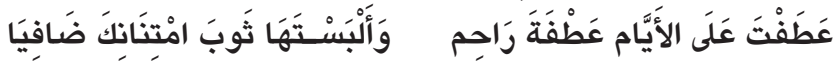

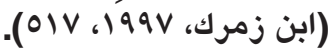
๑ء- الصفة: عروس. الدلالة: المرأة ما دامت في إعراسها (لسان 
r- الصفة: جامع. الدلالة: المرأة الحامل في بطنها ولد (لسان العرب ـ مادة جمع). صفة الدلالة: جسدية، حقل الدالالة: جسدي الدامي الدان

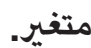
ع- الصفة: حائص. الدلالة: المرأة الرتقاء الضيقة الفرج (لسان

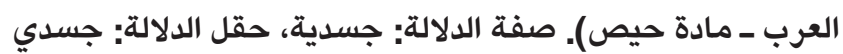
ثابت، ومن ذلك قول الشاعر ابن الرومي مستعيرا بها للملك:

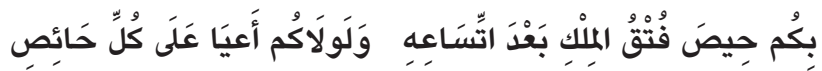

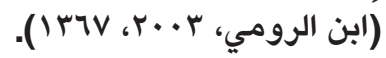

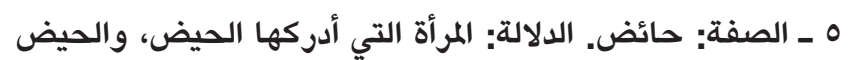

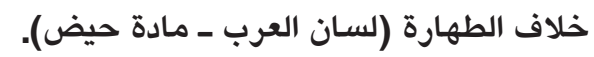

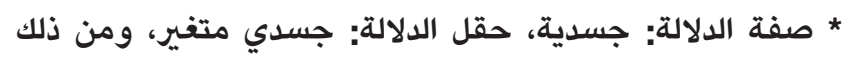

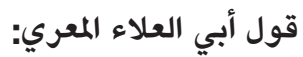

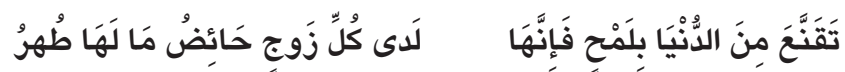

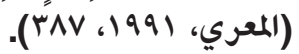

1 ـ الصفة: حاسو. الدلالة: المرأة التي حسرت عنها ثيابها (لسان

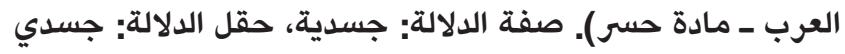

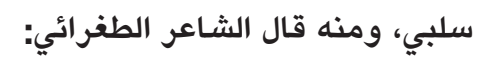
وَلَاَ هَجْعَةُ وَاللَّلْ عَدَرَاءُ نَاهِدُ فَلَا ضَجْعَةُ وَالصُبْحُح شَمْطَاءُ حَاسِر

$$
\text { (الطغرائي، دت، عV). }
$$

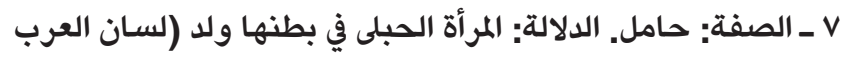

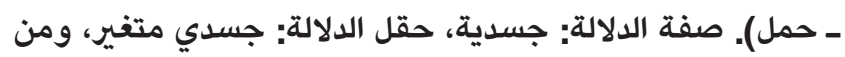
ذلك قول الشاعر ابن الرومي:

أَتَمَتْ شَخْصَهُ عِنْدَ الوِلَادِ

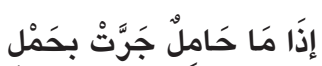

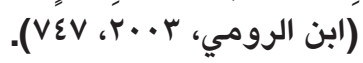

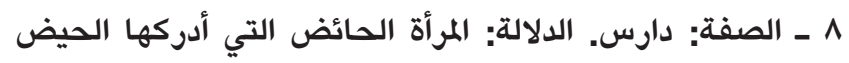

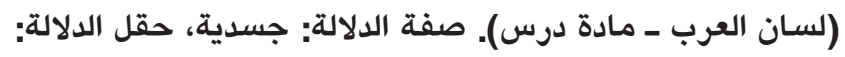

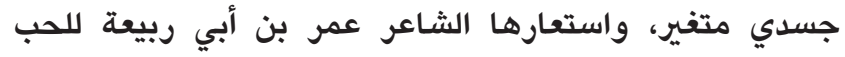

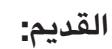

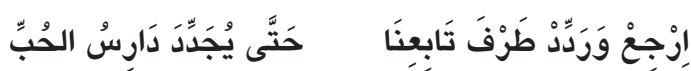

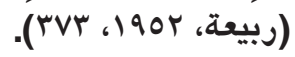

9 ـ الصفة: زائن. الدلالة: المرأة المتزينة (لسان العرب ـ مادة زين).

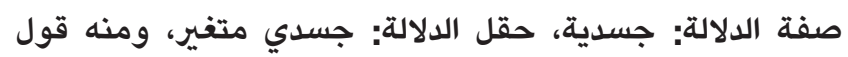

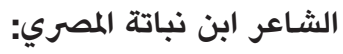
وَعَهِدِي بَأَنَّ الخَالَ لِلوَجْهِ زَائنُْ

فَيْبْصرُ وَجْهاً فِي الوَرَى زَانَ خَاله

$$
\text { (المصري، دت، 107) (107). }
$$

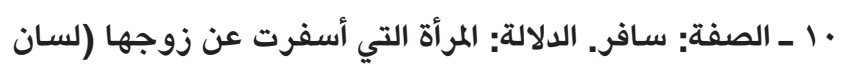

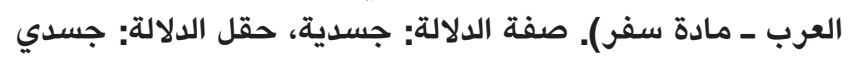

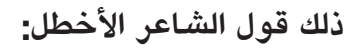

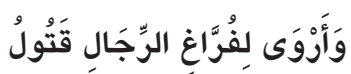

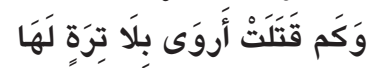

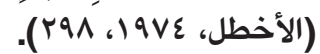

ror- الصفة: لعوب. الدلالة: المرأة عاشقة لزوجها متحبية إليه

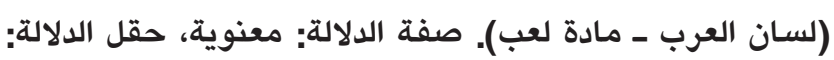
الزواج، ومن ذلك قول الشاعر المهلهل بن ربيعة:

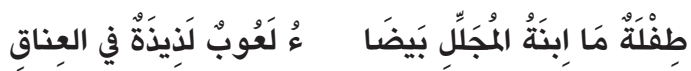

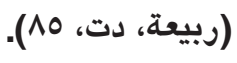

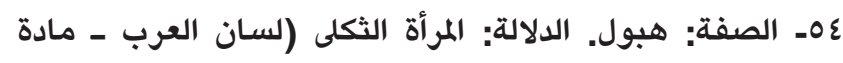

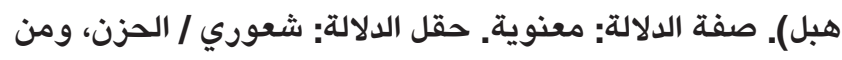

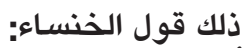
بَرَاهَا الدَّهرْ كَالعَظْمِ المَهِيضِ

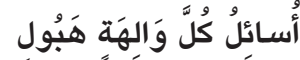

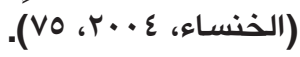

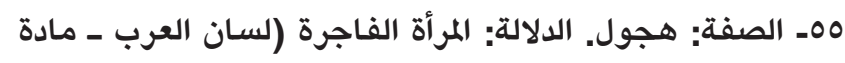

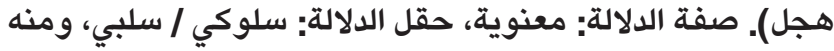
قول الشاعر المعري الذي أراد المرأة المتصنعة: مِنْ حُرَّةٍ مَا لَهَا فِي العَينِ جِلْبَابُ

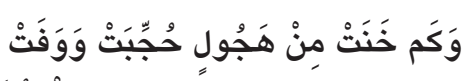

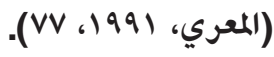

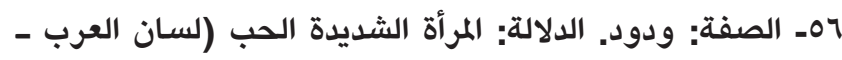

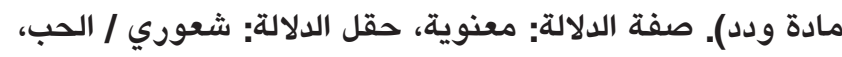
يقول الشاعر كشاجم الرملي: مالي: تَحتَّ ظِلِّ الصِّبَا وَوَصْلِ وَدُودِ أُقسِمُ الدَّهْرَ بَينَ وَصْلِ حَبيبِ

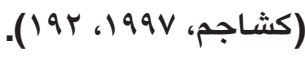
OV - OV

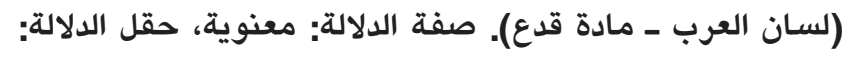

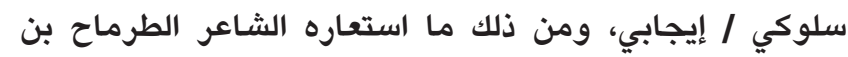
حكيم للصوت. إذا أشد الصوت للقوم دلئ ما ليظهر أنه معهم، نحو قوله:

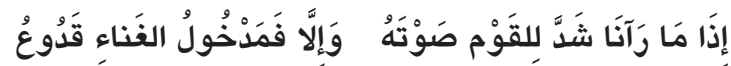

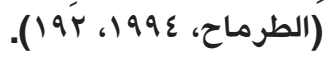
ثانيا ـ صفات المرأة في البنية الصرفية ـ فاعل.

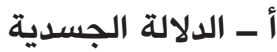
اــ الصفة: بادن. الدلالة: المرأة السمينة (لسان العرب ـ مادة

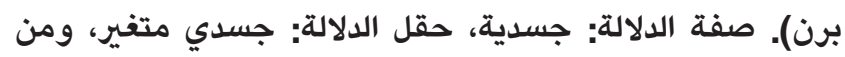
تُمِيلُ عَلى اللِيَتِينِ وَحَفاً مُرَجَّلا

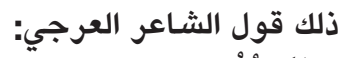

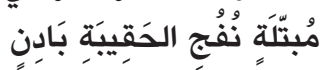

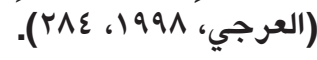

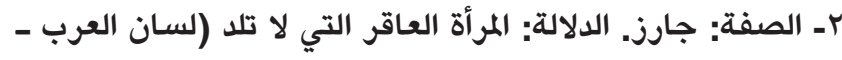

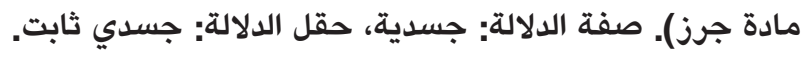


متغِيِ، ومن ذلك قوله تعالى في مريم عليها السلام:

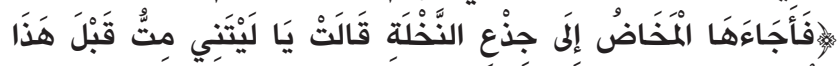

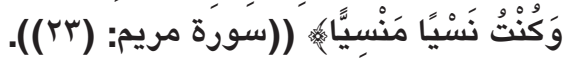
19 ـ الصفة: ناتق. الدلالة: المرأة الكثيرة الأولاد (لسان العرب ـ مادة نتق). صفة الدلالة: جسدية، حقل الدلالة: جسدي متغير، ومنه قول أبي العلاء المعري: ماده نيفي وَلَم يَحفَظُو بِالنُّنْكِ حُرْمَةَ نَاتِقِ هُمُ هَتَكْوُ بـالرَّاح أَسْتارَ عَاذلِ

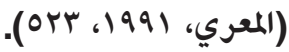
• · ـ الصفة: ناشئ. الدلالة: المرأة فويق المحتلمة (لسان العرب ـ

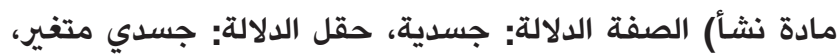
ومن ذلك قول الشاعر عمر بن أبي ربيعة:

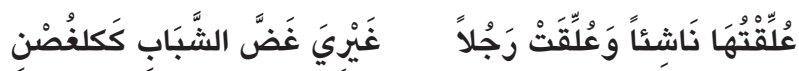

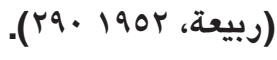

ا ب ـ الصفة: ناهد. الدلالة: المرأة إذا نهد ثديها(لسان العرب ــمادة نهد)، أي برز. صفة الدلالة: جسدية، حقل الدلالة: جسدي متغير، ومنه قول الشـاعر العباس الأحنف: رُمَّانْ صَدرِ لَيسَ يُقطَفْ نَاهِدُ

$$
\text { جَالَ الوشَاحُ عَلَى قَضِيبِ زَانَهُ }
$$

(الأحنف، ع (190،).

r ـ الصفة: هاجن. الدلالة: المرأة التي تتزوج قبل أن تبلغ، وهي

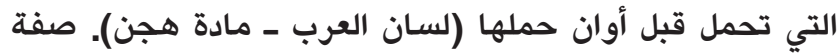
الدلالة: جسدية، حقل الدلالة: جسدي متغير، ومن ذلك قول الشاعر الطرماح بن حكيم:

فَلَمَّا ادَّرَكْنَاهُنَّ أَبْدَيْنَ للِهَوَى مَحَاسِنَ وَاستَوَلَينَ دُونَ مَحساسِنِ

وَلَيسَتْ بَأَدنَى غَيرَ أُنْس حَدِيثِهَا

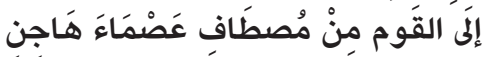

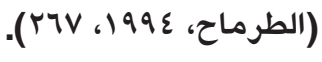

r ـ ـ الصفة: جالع. الدلالة: المرأة التي جلعت خمارها أي خلعته

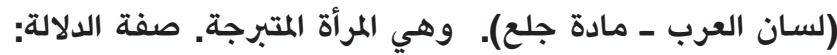

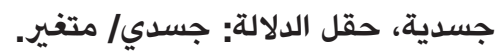

$$
\text { ب - الدلالة المعنوية. }
$$
ع ـ ـ الصفة: باخس. الدلالة: المرأة التي تبخس الحق (لسان العرب ـ مادة بخس). صفة الدلالة: معنوية، حقل الدلالة: سلوكي/ سلبي. ه ـ ـ الصفة: باهل. الدلالة: المرأة التي تمنع زوجها مالها (لسـان العرب ـ مادة بهل). صفة الدلالة: معنوية، حقل الدلالة: سلوكيا سلبي.

$$
\text { / حركي، يقول الشاعر عمر بن أبي ربيعة: }
$$$$
\text { إِلِنِنَا وَمُسْتَحْي رَآنَا فَصَارِفِ }
$$

يَطُفْنَ بِهَا مِثْلَ الدُمَى بَيْنَ سَافِرِ

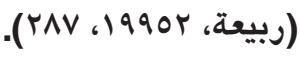

11 ـ الصفة: شارف. الدلالة: المرأة الحسنة الجميلة (لسان العرب مادة شرف). صفة الدلالة: جسدية، حقل الدلالة: جسدي ثابت. I ـ الصفة: طاهر. الدلالة: المرأة الطاهر من الحيض (لسان

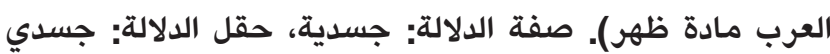
متغير، واستعيرت كثيرا للثوب في الشعر العربي كقول كثير عزة

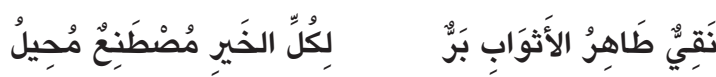

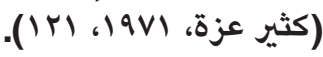

rا ـ الصفة: طامث. الدلالة: المرأة الحائض التي أدركها الطمث (لسان العرب ـ مادة طمث). صفة الدلالة: جسدية، حقل الدلالة:

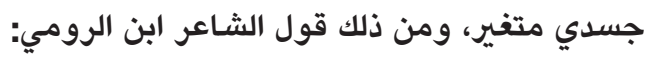

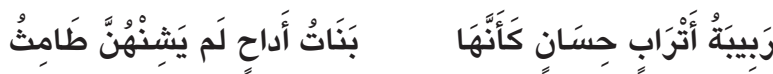

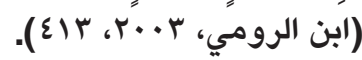

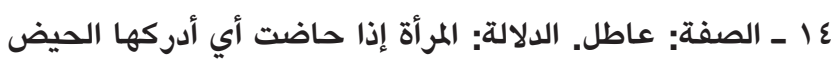
(لسان العرب ـ مادة عرك). صفة الدلالة: جسدية، حقل الدلالة:

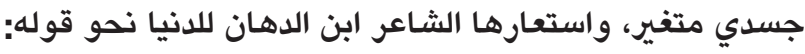
فَصِرِتَ لَهَا حُسناً وَصُفنَ لَهَا حُلَى

وَقَد كَانَت الدُنيَا كَشَوهَاءَ عَاطِل

(ابن الدهان، 1971، (01) - (0). 17 ـ الصفة: عاقر. الدلالة: المرأة التي لا تلد (لسان العرب ـ مادة عقر). صفة الدلالة: جسدية، حقل الدلالة: جسدي ثابت، ومن ذلك لك الك الكران قول الشاعر حاتم الطائي: وَقَد أَيْقَنْوا أَنَّهَا عَاقِرُ وَقَد زَوَّجُوهَها وَقَدْ عَنَسَتْ

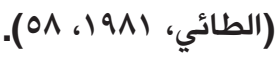

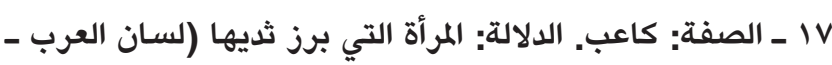
مادة كعب). صفة الدلالة: جسدية، حقل الدلالة: جسدي متفير، ومن ذلك قول الشاعر ابن حمديس: مُعَاوضَةَّة مِنْ جِيدِ غَيدَاءَ كَاعِب يَبِيتُ رِتَاسُ العَضْبِ فِي نِنْي سَاعِدِي

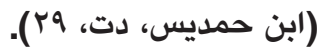
ومنه قوله: يَمُوتُونَ مَوتَ العِّزِ فِي حَوْمَةِ الوَغَى إذِا مَاتَ أَهلْ الجُبْنِ بَيْنَ الكَوَاعِبِ

(المرجع السابق، rr). 1 ـ الصفة: ماخض. الدلالة: المرأة ضربها المخاض (لسان العرب ـ مادة محض). صفة الدلالة: جسدية، حقل الدلالة: جسدي 
r ـ ـ الصفة: فاقد. الدلالة: المرأة التي إذا مات زوجها أو ولدها أو

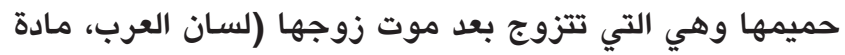

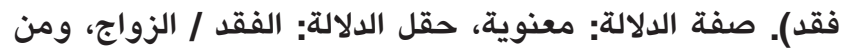
ذلك قول الشاعر الأعشى واستعارها للغزال:

عَلَّلى جَانِبَي تَثْلِيَّ تَبْنِي غَزَالَهَا

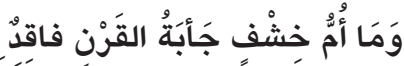

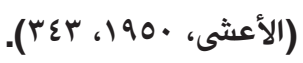

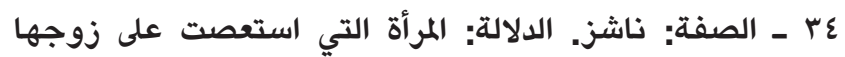

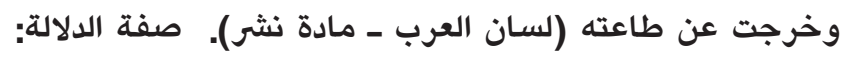
معنوية، حقل الدلالة: سلوكي/ سلبي، ومن ذلك قول الشان الشاعر

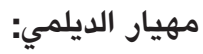

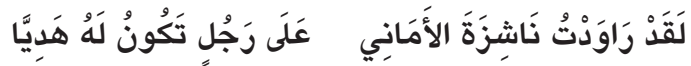

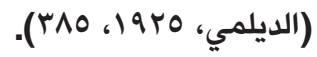
مr - الصفة: ناشص. الدلالة: المرأة التي كرهت زوجها (لسان السان

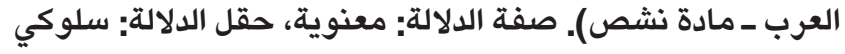
/ سلبي، ومن ذلك قول ابن الرومي: عَلَى بَعْلِهَا حَتَّى غَدَتْ غَيْرَ نَاشِصِ

وَكَنْ نَشَصَتْ مِنْ نِعْمَة فَعَطَفْتُهَا

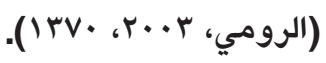

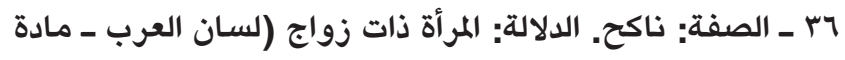

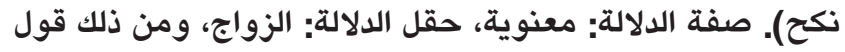

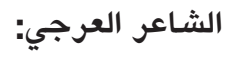
أَيَيا قَلَبُْ لَا تَكْلَفْ فَلَيَلَى مَزَارُهَها

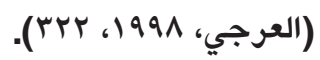

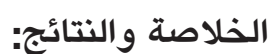
تمثلت صفات المرأة في البنية الصرفية للوزنين (فعول وفاعل) في

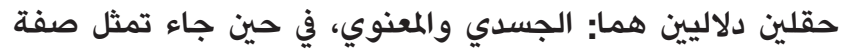

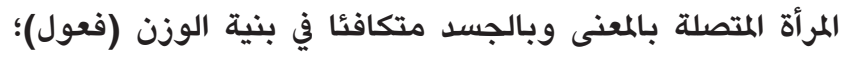

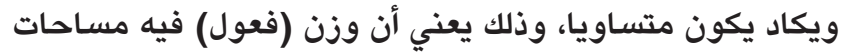

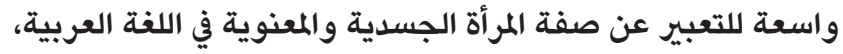
بيد أن هناك تفاوتا كبيرا وواضحا في دلالة الجسد في الوزن الجداة (فعول) إذ طفت حركة الجسد: الجانب الجسدي/ الحركي للمرأة فجاءت أناءت

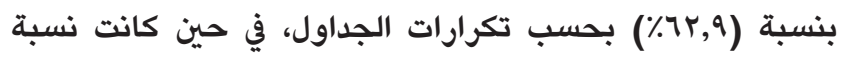

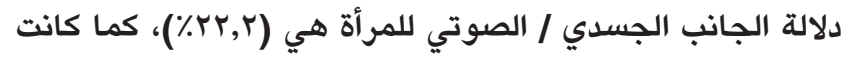

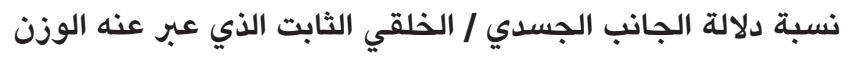

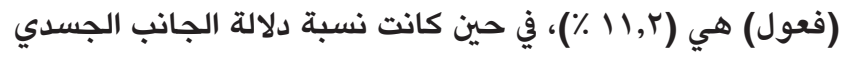

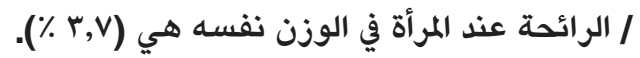

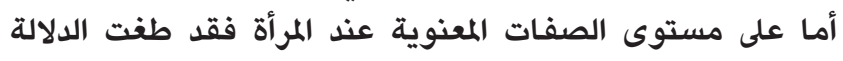

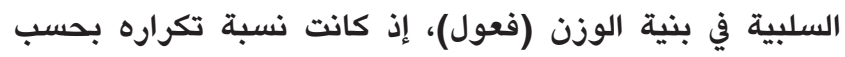

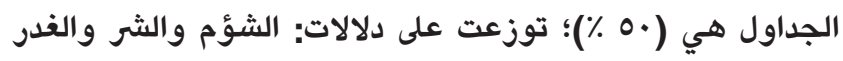

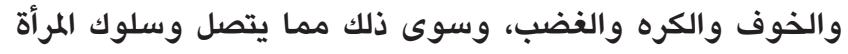
السلبي، في حين كانت نسبة الدلالة الإيجابية المتصلة بالزواج هي ولفي ولئل
Tl ـ الصفة: جامح. الدلالة: المرأة التي تجمح عن زوجها أي إلي

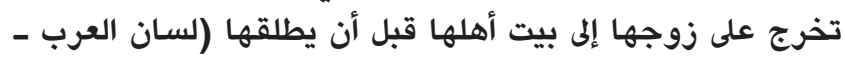
مادة جمح). صفة الدلالة: معنوية، حقل الدلالة: سلوكي/ سلبي. الصفة ـV الصف: راجح. الدلالة: المرأة إذا مات زوجها رجعت إلى أهلها

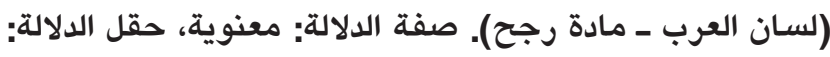

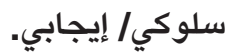
العرب - الصفة: طالق. الدلالة: المرأة التي طلقها زوجها (لسان الدان

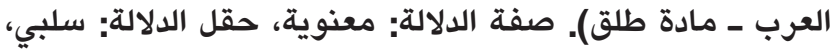
ومنه قول الشاعر ابن رشيق القيرواني: مفة الالة: معنوية وَمِنْ بَعدِهِ أُمُّم السُّرورِ عَقِيمُ وَمِنْ بَعِدِهِ زَوْجُ الخَلاعَة طَالِقِ

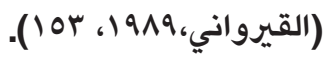
ومنه قول الشاعر بهاء الدين زهير على الاستعارة: وَأَمَّا سِوَاهَا فَهْيَ مِنِِّ طَالقِق

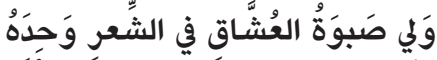

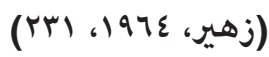

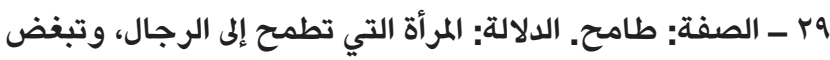

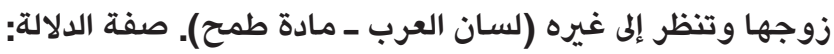

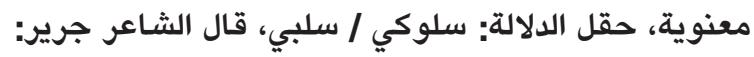
بمَطْرُوفَةِ العَينَين شَوسَاءَ طَامِح

إذَا ذَكَّرَتْ زَيدًا تَرَقْرَقَ دَمْعُهَا

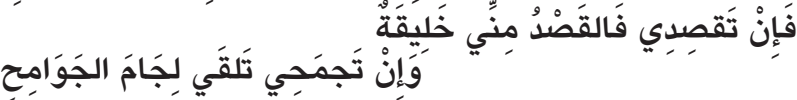

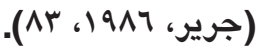

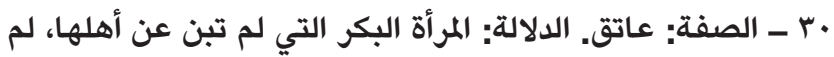

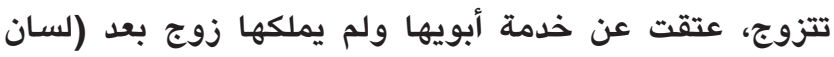

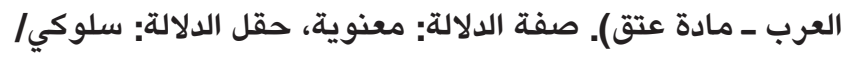
إيجابي، ومن ذلك قول الشاعر ابن الأبار: بَمَنْظُومَة كَالعِقْدِ فِي نَخْرِ عَاتِقِق مَنَنْتَ بهَا مَنْثُرَرَة وَشَفَعْتَهَا

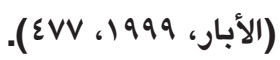
الب ـ الصفة: عاهر. الدلالة: المرأة الزانية التي تتبع الشر(لسان

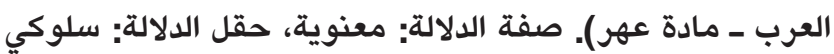
/ سلبي، ومن ذلك قول الشاعر البحتري:

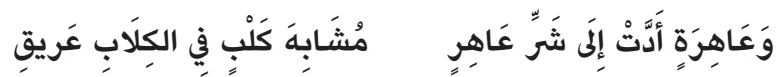

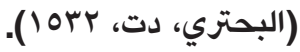

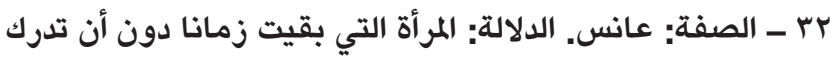

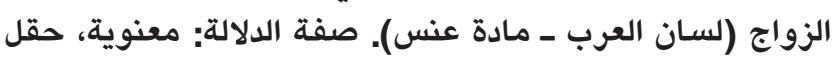

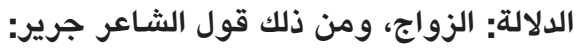
عَنْ الزَّوْجُ أَوْ مَنْسُوبَّة الحَال عَانس

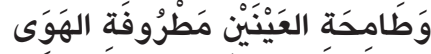

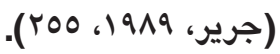


وجاءت بنسبة (ع,ع٪)، بناء على نسبة التكرارات في الجداول.

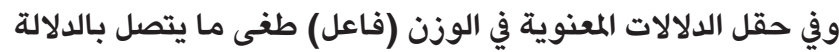

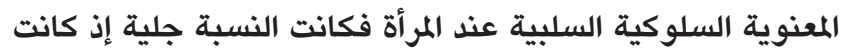
نسبة التكرار هي (,01\%) وهذا يعني تمتع بنية الوزن (فاعل) بمساحات كبيرة؛ ليعبر عن صفات المرأة المعنوية السلوكية

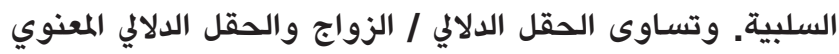

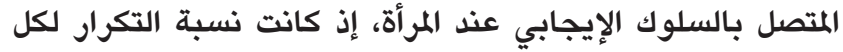

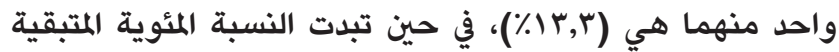
وقدرها (V,7\%) في حقل الدلالة المعنوي المتصل بالفقد عند المرأة.

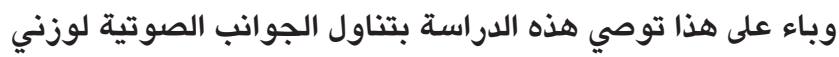
(فعول) و(فاعل) وأثر ذلك في مدى تداول الصفات التي يستوي

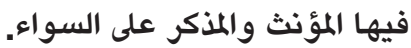

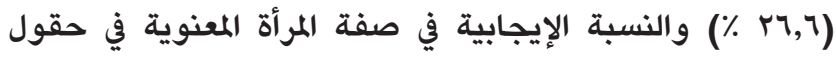

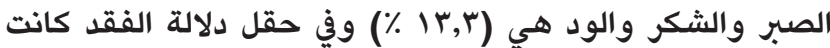

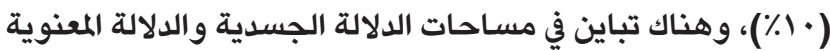

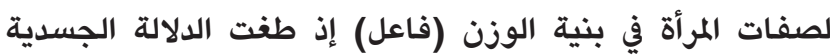
وكانت بنسبة (^,rاף \%) في حين كانت نسبة الدلالة المعنوية في

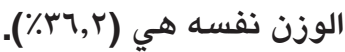
في الجانب الجسدي طغت الدلالة الجسدية المتفيرة في صفة المرأة في

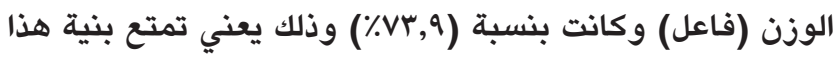

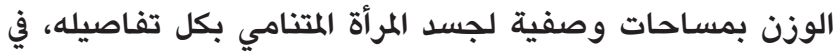

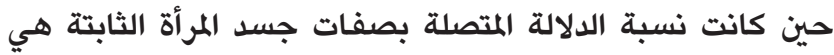
وعا,V)

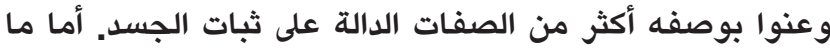
يتصل بالدلالة الجسدية السلبية في صفات المرأة فكانت قليلة

الملاحق

\begin{tabular}{|c|c|c|c|c|c|c|c|}
\hline \multicolumn{2}{|c|}{ الوزن (فاعل). الحقل الدلالي (المعنوي) } & \multicolumn{2}{|c|}{ الوزن (فاعل). الحقل الدلالي: جسدي } & \multicolumn{2}{|c|}{ الوزن فعول. الحقل الدلالي: معنوي } & \multicolumn{2}{|c|}{ الوزن فعول / الحقل الدلاي: جسدي } \\
\hline صفة الدلالة(معنوي) وحقلها & باخس & جسدي / متغير & بادن & معنوي / سلبي / شؤم & بسوس & جسدي / حركي & جروز \\
\hline معنوي / سلوكي / سلبي & باهل & جسدي / متغير & جامع & معنوي / سلبي/ شر & حسود & جسدي / حركي & جفول \\
\hline معنوي / سلوكي / سلبي & جامح & جسدي / متغير & 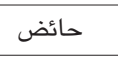 & معنوي / سلبي/ غدر & 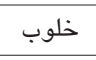 & جسدي / حركي & 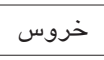 \\
\hline معنوي / سلوكي / سلبي & طالق & جسدي / متغير & حامل & معنوي / سلبي/ سلوك & قتول & جسدي / حركي & خفوت \\
\hline معنوي / سلوكي / سلبي & طامح & جسدي / متغير & دارس & معنوي / سلبي/ سلوك & 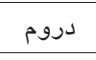 & جسدي / حركي & 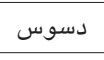 \\
\hline معنوي / سلوكي / سلبي & عاهر & جسدي / متغير & زائن & معنوي / سلبي/ خوف & 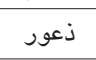 & جسدي / حركي & 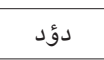 \\
\hline معنوي / سلوكي / سلبي & 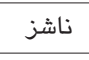 & جسدي / متفير & طاهر & معنوي / سلبي / سلوك & ل أؤود & جسدي / حركي & ربوخ \\
\hline معنوي / سلوكي / سلبي & ناشص & جسدي / متغير & سافر & معنوي / سلبي/ سلوك & صيود & جسدي / حركي & طروح \\
\hline معنوي / سلوكي / سلبي & عانس & جسدي / متغير & طامث & معنوي / سلبي / الكره & 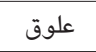 & جسدي / حركي & | ل عدوس \\
\hline معنوي / الزواج & ناكح & جسدي / متغير & عارك & معنوي / سلبي / الغدر & غدور & جسدي / حركي & عسوس \\
\hline معنوي / الزواج & راجع & جسدي / متغير & كاعب & معنوي / سلبي/ الغضب & غضوب & جسدي / حركي & فشوش \\
\hline معنوي / سلوكي / إيجابي & عاتق & جسدي / متغير & 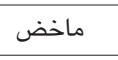 & معنوي / سلبي / خوف & فروق & جسدي / حركي & كفوت \\
\hline \multirow[t]{18}{*}{ معنوي / سلوكي / إيجابي } & 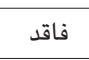 & جسدي / متغير & ناتق & معنوي / سلبي/ سلوك & 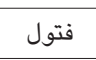 & جسدي / حركي & لفوت \\
\hline & & جسدي / متغير & ناشئ & معنوي / سلبي/ سلوك & هجول & جسدي / حركي & مصوص \\
\hline & & جسدي / متغير & ناهد & معنوي / سلبي/ سلوك & قرود & جسدي / حركي & نعوس \\
\hline & & جسدي / متغير & هاجن & معنوي / الزواج & بروك & جسدي / حركي & 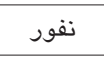 \\
\hline & & جسدي / متغير & جالع & معنوي / الزواج & بتول & جسدي / حركي & هلوك \\
\hline & & جسدي / ثابت & جارز & معنوي / الزواج & حنون & جسدي / حركي - صوتي & ع عروب \\
\hline & & جسدي / ثابت & حائص & معنوي / الزواج & ظنون & جسدي / صوتي & خبوق \\
\hline & & جسدي / ثابت & شارف & معنوي / الزواج & عروس & جسدي/ صوتي & حضوف \\
\hline & & جسدي / ثابت & عاطل & معنوي / الزواج & عطوف & جسدي / صوتي & 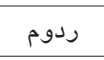 \\
\hline & & جسدي / ثابت & عاقر & معنوي / الزواج & فروك & جسدي / صوتي & سكوت \\
\hline & & جسدي / سلبي & حاسر & معنوي / الزواج & ل لعوب & جسدي / صوتي & 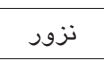 \\
\hline & & & & معنوي / إيجابي / الصبر & صبود & جسدي / ثابت (خلْقي) & 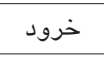 \\
\hline & & & & معنوي إيجابي / الشكر & شكود & جسدي / ثابت (خلقي) & ق تشور \\
\hline & & & & معنوي / إيجابي / الود & ودود & جسدي / ثابت (خلقي) & نكوع \\
\hline & & & & معنوي إيجابي & قدوع & جسدي / رائحة & أنوف \\
\hline & & & & معنوي / الفقد & ثكول & & \\
\hline & & & & معنوي / الفقد & عجول & & \\
\hline & & & & معنوي / الفقد & هبول & & \\
\hline
\end{tabular}




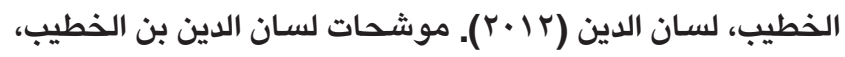

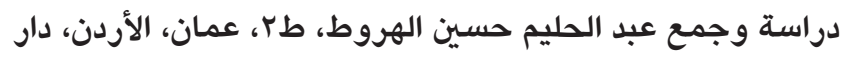
جرير للنشر والتوزيع.

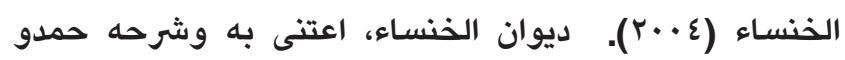
طماس، ط r، دار المعرفة بيروت، لبنان، دار المعرفة. ابن الدهان (1971). ديوان ابن الدهان أبو الفرج مهذب الدين بن

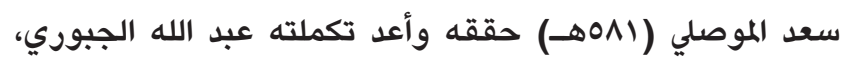
طا، بغداد، مطبعة المعارف.

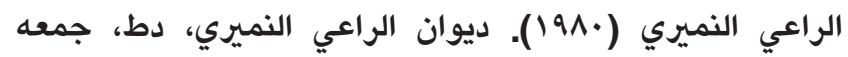

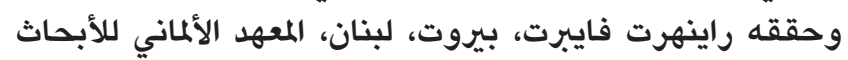

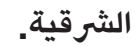

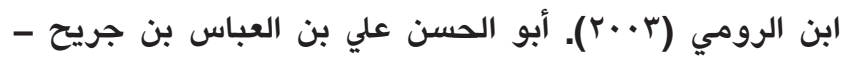

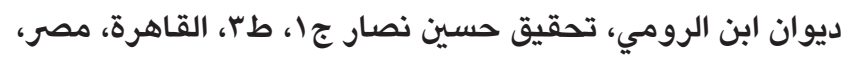

$$
\text { مطبعة دار الكتب والوثائق المصرية. }
$$

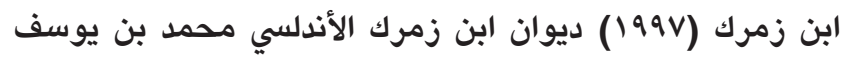

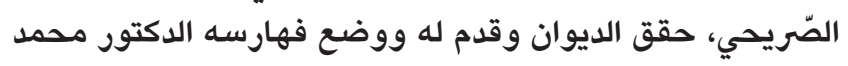
توفيق النيفر، طا، بيروت، لبنان، مؤسسة الرسالة.

ابن زيدون (ع999 ) ديوان ابن زيدون، شرح يوسف فرحات، طץ، بيروت، لبنان، دار الكتاب العربي.

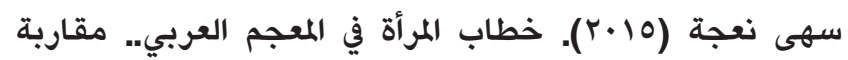
سوسيولغوية، طا، إربد، الأردن، عالم الكتاب الحديث.

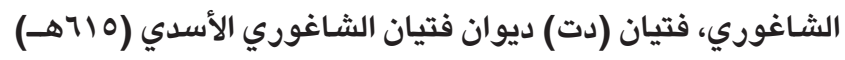

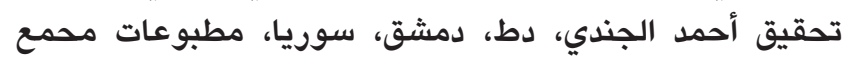

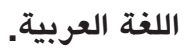

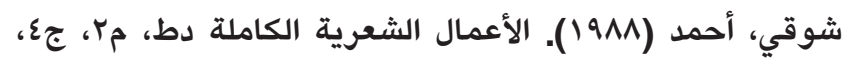

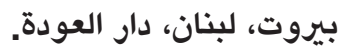

صريع الفواني(دت) مسلم بن الوليد الأنصاري (^• بهــ) - ديوان

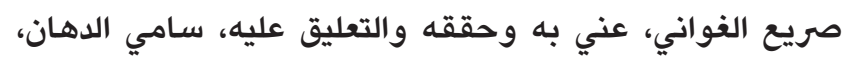

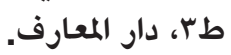

الصنوبري (1991). ديوان الصنوبري أحمد محمد بن الحسن الضبي، تحقيق إحسان عباس، طا، بيروت، لبنان، دار صادر. الطائي، حاتم (1911) ديوان حاتم الطائي، بيروت، لبنان، دار

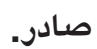

ابن طباطبا (دت) محمد بن أحمد - عيار الشعر، طب، شرح

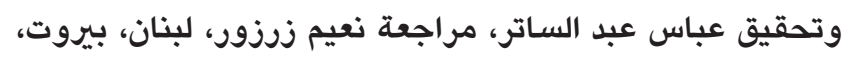

المراجع

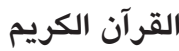

إبراهيم إبراهيم بركات (9M1) (191. التأنيث في اللغة العربية، طاء، دار

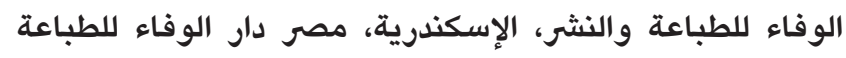

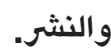

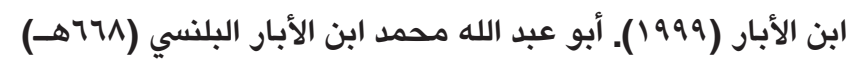

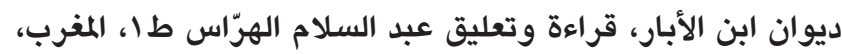

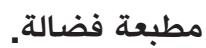

الأخطل (ع 199). ديوان الأخطل، شرحه وصنف قوافيه وقدم له مهدي محمد ناصر الدين، ط؟، ، بيروت، لبنان، دار الكتب العلمية.

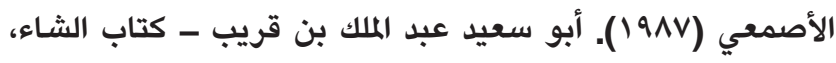

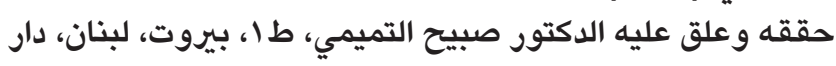

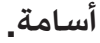

الأعشى (9001). ميمون بن قيس - ديوان الأعشى الكبير، تحقيق

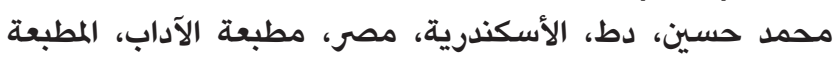

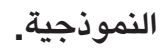

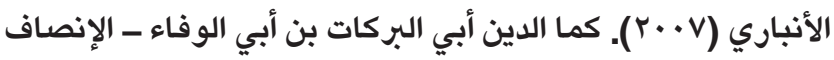

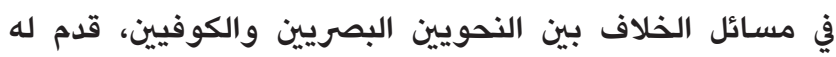
ووضع هوامشه وفهارسه حسن حمد، بإشراف الدكتور إميل بديع يعقوب، ط r ب، لبنان، بيروت، دار الكتب العلمية. البحتري (دت) ديوان البحتري، تحقيق حسن كامل الصيرفي، طب، مصر، دار المعارف ذخائر العرب.

بهاء الدين زهير (عاد) (197). ديوان بهاء الدين زهير(707هـ)، دط،

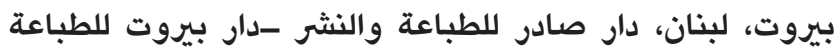

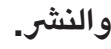

جرير (917) داع ديوان جرير، كرم البستاني، دط، بيروت، لبنان،

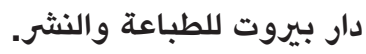

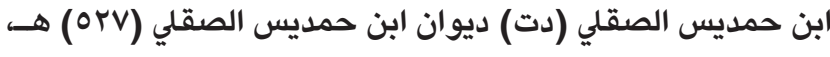
دط، دار صادر، صححه وقدمه إحسان عباس، بيروت، لبنان.

ابن حيوس (ع/91). ديوان ابن حيوس، عني بنشره وتحقيقه خليل مردم بك جا، بيروت، لبنان دار صادر.

الحيص بيص (19Vع). ديوان الأمير شهاب الدين أبي الفوارس (حس

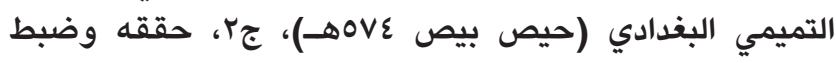

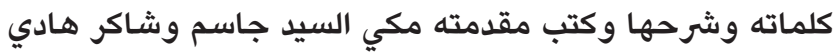

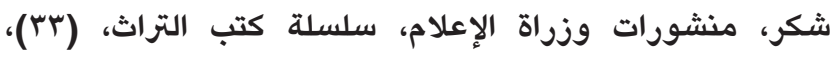

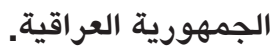




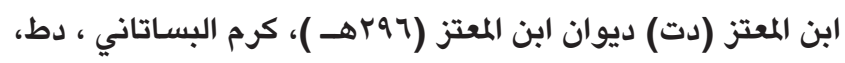
بيروت، لبنان، دار صادر.

المعري، أبو العلاء (190V) سقط الزّند، دط، بيروت، لبنان، دار بيروت للطباعة والنثر، دار صادر للطباعة والنثر.

المعري، أبو العلاء (1991). لزوميات أبي العلاء، شرح السيد البطليوسي، حققه وقدم له الدكتور حامد عبد المجيد، الهيئة المصرية العامة للكتاب، القسم الأول، مصر.

ابن منظور(دت) محمد بن مكرم الإفريقي المصري

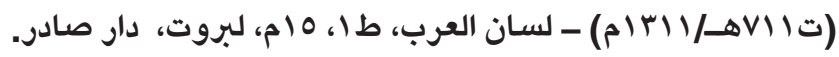
المهلهل بن ربيعة (دت) ديوان المهلهل بن ربيعة، شرح وتقديم طلال حرب، د.ط، الدار العالمية.

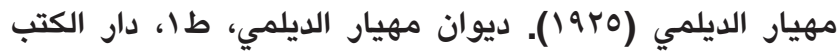
المصرية، الطبعة المصرية، القاهرة، مصر، الطبعة المصرية. النابغة الذبياني (1997). ديوان النابغة الذبياني، شرح وتقديم عباس عبد الساتر، طا، بيروت، لبنان، دارالكتب العلمية.

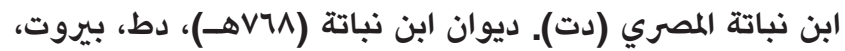
لبنان، دار إحياء التراث العربي.

ابن هانئ الأندلسي (·191) ). ديوان ابن هانئ الأندلسي، تقديم كرم

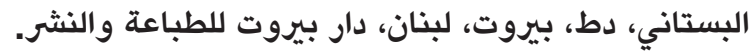
الهذليين، الشعراء (1970). ديوان الشعراء الهذليين، القسم الأول،

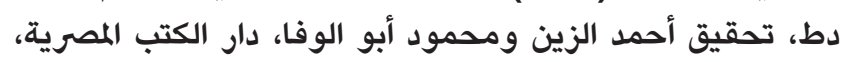
مصر.

ابن هشام الأنصاري (دت) أوضح المسالك إلى ألفية ابن مالك ومعه

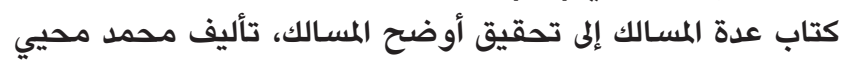

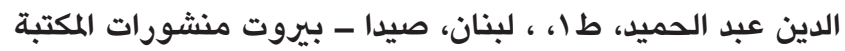

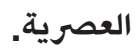

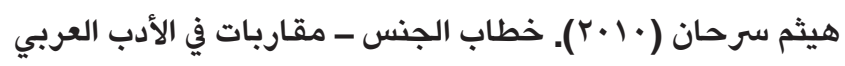
القديم، ط (ا،بيروت، لبنان، المركز الثقافي.

العربي.الوأواء الدمشقي (1900). ديوان الوأواء الدمشقي، عني

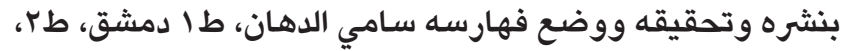
بيروت لبنان دار صادر.
منشورات محمد علي بيضون.

الطرماح بن حكيم (ع991). ديوان الطرماح بن حكيم، تحقيق

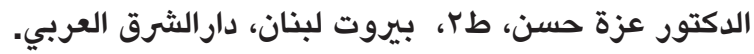

الطغرائي (دت) ديوان الطغرائي، طا، مطبعة الجوائب، قسطنطينية، . . أهـ.

العباس بن الأحنف (ع019). ديوان العباس بن الأحنف، شرح

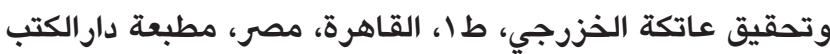
المصرية.

العجاج، رؤبة (1971) مجموع أشعار العرب، دط، اعتنى بتصحيحه وترتيبه وليم بن الورد البروسي، الكويت، النقرة، دارابن قتيبة للطباعة والنشر والتوزيع.

العرجي (1991). ديوان العرجي، جمعه وحققه وشرحه الدكتور

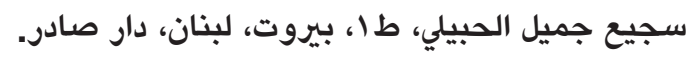
عمر بن أبي ربيعة (190r) مهرح ديوان عمر بن أبي ربيعة، تأليف محمد محيي الدين عبد الحميد، طا، مصر، مطبعة السعادة.

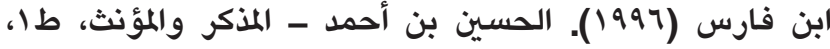
حققه وقدمه وعلق عليه الدكتور رمضان عبد التواب، القاهرة.

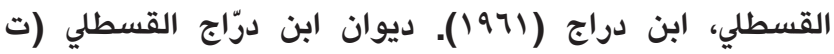

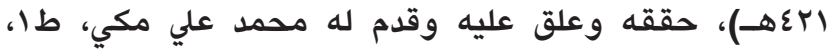

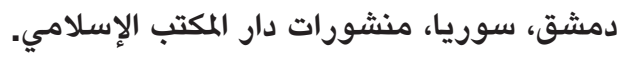

القـيرواني، ابن رشيق (9199). ديوان ابن رشيق القيرواني، جمعه ورتبه عبد الرحمن ياغي، دط، ، بيروت، لبنان، دار الثقافة.

قيس بن الملوح (999 (199). ديوان قيس بن الملوح مجنون ليلى، رواية

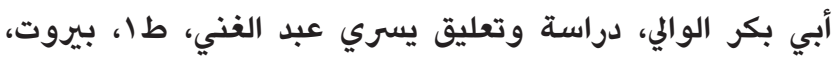
لبنان، دارالكتب العلمية. كثير عزة (19VI). ديوان كثير عزة، جمعه وشرحه إحسان عباس، دط، بيروت، لبنان، دار الثقافة.

كشاجم (199V). محمود بن الحسين - ديوان كشاجم، تحقيق عبد الواحد شعلان، ط اج، القاهرة، مصر، مكتبة الخانجي. المبرد ( · PV ). أبو العباس محمد بن يزيد ـ المذكر و المؤنث، حققه وقدم له وعلق عليه الدكتور رمضان عبد التواب وصلاح الدين

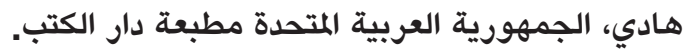
المتنبي (19^r). ديوان المتنبي، دط، بيروت، لبنان. دار بيروت للطباعة و النثر. 